\title{
PSICOTERAPIA DO PONTO DE VISTA DE UM COMPORTAMENTALISTA ${ }^{I}$
}

\section{PSYCHOTERAPY FROM THE STANDPOINT OF A BEHAVIORIST}

\author{
Charles. B. Ferster
}

\begin{abstract}
RESUMO
O processo pelo qual o comportamento dos organismos é adquirido, modelado e eliminado, durante suas transaçôes com o ambiente, é o tema central das formulaçôes da psicopatologia e da psicoterapia. A análise funcional do comportamento de Skinner afirma que a descoberta de como variáveis ambientais controlam o comportamento pode substituir explicações mentalistas e explicações fisiológicas inferidas. Uma característica proeminente daqueles que realizaram as primeiras contribuições comportamentais ao estudo da doença mental era seu forte envolvimento com a pesquisa básica com animais no início de suas carreiras e sua posterior preocupação com a aplicação desse conhecimento aos problemas humanos. As abordagens comportamentais aos problemas clínicos, com sua ênfase na aplicação de princípios de aprendizagem, opuseram-se também ao uso da epistemologia da vida mental e do "modelo médico". Uma importante contribuição de uma psicologia comportamental é a linguagem sobre a conduta humana. A análise funcional do comportamento operante pode servir como uma linguagem para converter o conhecimento encoberto, derivado da experiência, em termos objetivos e possibilitar que as práticas sejam refinadas pela experiência e comunicadas. Esse texto apresenta as bases conceituais e as contribuições metodológicas da psicologia operante, explorando, em seguida, as possibilidades de uma análise funcional das interações terapeutapaciente, com ênfase especial no papel do comportamento verbal.
\end{abstract}

Palavras-chave: psicoterapia, psicopatologia, interaçōes paciente-terapeuta

\begin{abstract}
The processes by which the behavior of organisms is acquired, shaped, and eliminated during the organism's transaction with the environment is the central theme of behavioral formulations of psychopathology and psychotherapy. Skinner's functional analysis of behavior asserted that the discovery of how environmental variables controlled behavior could substitute for mentalistic and inferred physiological explanations. A prominent characteristic of those who made the first behavioral contributions to the study of mental illness was their sustained involvement in basic animal research and their concern with applying this knowledge to human problems. Behavioral approaches to clinical problems, in addition to their emphasis on applying learning principles, also opposed the use of the epistemology of the metal life and the "medical model". An important contribution of the behavioral psychology is a language about human conduct. The functional analysis of operant behavior can serve as a language to convert experiential knowledge to objective terms so that practices can be refined by experience and communicated. The present text presents the conceptual basis and methodological contributions of operant psychology and explores the possibilities of a functional analysis of the interactions between patient and therapist, emphasizing the role of verbal behavior.
\end{abstract}

Key words: psychotherapy, psychopathology, patient-therapist interactions

O processo pelo qual o comportamento dos organismos é adquirido, modelado e eliminado, durante suas transações com o ambiente, é o tema central das formulações de psicopatologia e psicoterapia. As tradições de Pavlov, Hull e Skinner salientaram a plasticidade do comportamento humano, principalmente através das descobertas em laboratório com animais. Os experimentos de Pavlov com o reflexo condicionado em cães e as extensões de Watson para seres humanos conduziram às aplicações dos princípios de aprendizagem à psicopatologia. Ambos criaram modelos de patologia comportamental no laboratório e as trataram manipulando as mesmas variáveis pelas quais cada patologia foi

\footnotetext{
1 Artigo originalmente publicado em 1979 como o Capítulo 12 do livro Psychopathology in Animals, Editado por J. D. Keehn, ISBN 0-12-403050-5, pela Academic Press Inc. Tradução de Rachel Rodrigues Kerbauy (Universidade de São Paulo) revisado por Deisy das Graças de Souza (Universidade Federal de São Carlos). Resumo e abstract extraídos do texto pelas tradutoras; a publicação original não incluía resumo.
} 
criada. Pavlov observou o subproduto "neurótico" dos procedimentos do condicionamento salivar. Watson, no experimento que fez o menino Alberto temer objetos de pêlo, criou uma disfunção pelo condicionamento reflexo da resposta a um ruído forte. A tentativa de reverter a disfunção empregou os mesmos processos, em um procedimento semelhante ao que Wolpe, posteriormente, denominou inibição recíproca e relaxamento progressivo. Apesar da epistemologia de causas cerebrais do comportamento de Pavlov e da construção de variáveis intervenientes neurológicas de Hull (1943), todos esses programas pioneiros de pesquisa compartilhavam a noção de que os processos comportamentais eram ordenados e controlados pelo ambiente. A análise funcional do comportamento de Skinner, a mais recente explicação sobre o mesmo tema, asseverou que a descoberta de como as variáveis ambientais controlam o comportamento poderia substituir as explicações mentalistas e fisiológicas inferidas. O behaviorismo radical de Skinner estabeleceu um modelo de um programa de pesquisa que alcançou grande magnitude no controle do comportamento do organismo individual.

\section{Terapias Comportamentais Como Metáfora \\ Do Controle Comportamental}

Uma característica proeminente daqueles que realizaram as primeiras contribuições comportamentais ao estudo da doença mental era seu forte envolvimento com a pesquisa básica com animais no inicio de suas carreiras e sua posterior preocupação com a aplicação desse conhecimento aos problemas humanos. Apesar da preocupação primordial de Pavlov com a pesquisa técnica de laboratório, ele se refere à patologia humana e a aplicações aos problemas humanos em sete de suas 23 aulas, que resumem o trabalho de sua vida (Pavlov, 1927). Na aula 20 , por exemplo, ele escreveu sobre "a gravidez imaginária e outros tipos de doenças imaginárias". John B. Watson (1968), que se empenhou, nos 20 anos iniciais de sua carreira, em pesquisa básica com animais, contribuiu no experimento com o pequeno Alberto, em colaboração com Raynor, no momento em que estava saindo de seu trabalho acadêmico no laboratório. O livro Behaviorismo (Watson, 1919, 1930), que estava destinado a ser o clarim de chamada do behaviorismo, foi publicado depois que ele deixou o trabalho de laboratório. Em 1953 Skinner concentrou-se em escrever Ciência e comportamento humano e aplicar os princípios do condicionamento operante à educação, à psicoterapia, e a outras iniciativas sociais amplas. A carreira daqueles que, como Azrin, Ferster e Sidman, passaram de uma intensa dedicação à pesquisa básica com animais, para o trabalho em hospitais de doenças mentais, escolas para retardados, educação, psicoterapia, e extensões teóricas dos princípios de reforçamento operante aos problemas de depressão, obesidade, e da origem da doença mental, espelhou-se na carreira dividida de Skinner. Para cada um desses cientistas, os resultados conseguidos com a pesquisa animal levaram à convicção de que os métodos poderiam ser expandidos de modo efetivo e poderoso para as preocupações com os humanos. $\mathrm{O}$ condicionamento operante teve um impacto especial naqueles interessados na extensão das descobertas do laboratório aos problemas clínicos, talvez porque tantas das características do trabalho de laboratório da psicologia operante estavam de pleno acordo com os procedimentos clínicos, particularmente 
a ênfases no comportamento dos sujeitos individuais, mais do que as médias dos grupos e a inferência estatística (Ferster, 1974).

A experiência de condicionar um pombo, muitas vezes relatada tanto por iniciantes quanto por profissionais, ilustra a valorização especial que liga muitos psicólogos experimentais ao campo clínico. O experimentador, entrando em contacto com o animal apenas por meio de um botão, aumenta instantaneamente a freqüência de um ato e o modela em uma nova forma complexa, em questão de minutos. É necessária uma dose adequada de arte, mais do que uma aplicação mecânica, mesmo que o experimentador saiba que certamente cedo ou tarde, ele produzirá o comportamento condicionado. A interação tem um forte sabor clínico porque o experimentador precisa observar os detalhes do comportamento do pombo e ajustar suas ações às peculiaridades do comportamento da ave individual. Nenhum pombo é tão difícil que o experimentador não possa ser bem sucedido e nenhuma tarefa é difícil demais para ser tentada. A demonstração mostra o controle ordenado do comportamento e esclarece como os procedimentos de reforçamento interagem com o comportamento da ave para produzir o resultado esperado. Mas o que é especialmente importante, é que o experimento também demonstra outro aspecto do controle: a habilidade que o experimentador adquire. Ele ou ela estabelece como alvo o aumento da freqüência de um ato particular, pressiona o botão que apresenta o reforçador, e instantaneamente, vê o aumento dramático em sua freqüência. Quando o experimentador deixa de pressionar o interruptor, o comportamento torna-se menos freqüente e desaparece. Ele tem a sensação tanto de ter criado, como diminuído um comportamento. É um evento dramático, compartilhado por muitos daqueles com intenso investimento em psicologia comportamental, o que explica como tantos experimentadores na tradição operante encaminham-se para os limites entre a ciência natural e a prática clínica.

Essa metáfora do controle estendeu-se ainda mais com as pesquisas sobre esquemas de reforçamento com pombos (Ferster \& Skinner, 1957), que permitia antecipar um milhão de bicadas por mês em um sujeito individual, como também controlar detalhadamente, momento a momento, aspectos do comportamento do animal. A experiência reforçou a convicção, como acontecera com os resultados do experimento de Watson-Raynor com Alberto, de que o comportamento é plástico e que a patologia humana pode ser igualmente reversível se a submetermos a contingências de reforçamento análogas. Esse estilo de pesquisa, no qual a variável dependente era a freqüência do desempenho de um sujeito individual, deu um ar clínico às pesquisas do laboratório de condicionamento operante. Os procedimentos experimentais eram ajustados continuamente, dependendo do comportamento do sujeito; os fatores responsáveis pela singularidade do animal eram levados em consideração, os animais cujo comportamento se desviava do esperado não eram automaticamente descartados; e mudanças no comportamento tinham magnitude suficiente para terem utilidade prática.

Walden Two (Skinner, 1948), uma ficção sobre um modelo de sociedade na qual uma vida ótima era construída baseando suas práticas e tipos de controle em princípios de comportamento, funcionou como um poderoso estimulante, mais ou menos como o experimento com Alberto, para a idéia de 
que uma vida utópica poderia ser alcançada pela aplicação dos princípios comportamentais.

Não é tão surpreendente que tantos cientistas tenham reagido ao sucesso com que controlavam o comportamento no laboratório como um prelúdio para estender suas habilidades e descobertas aos problemas humanos. Além de sua utilidade inerente, a solução dos problemas humanos práticos é uma fuga do isolamento social do laboratório teórico, onde a primeira tarefa poderia ser definida como "descobrir mais e mais sobre menos e menos." O laboratório é um empreendimento solitário no qual as descobertas abstratas freqüentemente não têm uma ligação direta com atividades práticas, e onde é não somente possível, como desejável, criar e estudar fenômenos que podem não existir na natureza. Conquistas significativas do laboratório geralmente requerem esforço constante, longo e intenso e o pesquisador trabalha sem colaboração e apoio de seus colegas.

É paradoxal que Freud, que serviu como contraste para tantos que defenderam o estudo e o tratamento do comportamento humano como ciência natural, tenha vindo de uma tradição semelhante à de Pavlov, Watson e Skinner. Por um período de 20 anos, desde a escola de medicina até iniciar a prática clínica, Freud estava interessado principalmente na histologia, neurofisiologia, neuro-anatomia e neurologia, gastando mais tempo no microscópio que como clínico. É geralmente aceito que a epistemologia da vida mental de Freud é uma metáfora de seu conhecimento do arco reflexo. Foi o sucesso com o poder da ciência natural no laboratório, misturado com o isolamento social do trabalho, que conduziu
Freud, assim como Pavlov, Watson e Skinner, ao trabalho prático com pessoas.

É tentador especular que o pequeno impacto que Lewin (1935), Guthrie (1935) e Tolman (1932) tiveram na extensão das leis básicas da aprendizagem aos problemas clínicos esteja relacionado à ausência de um envolvimento substancial na pesquisa técnica de laboratório que alcançou controle explícito sobre o comportamento. Na mesma linha, não surpreende que Miller $(1941,1944)$ e Salomon (1977), cujas pesquisas com animais no laboratório adquiriram considerável controle sobre o comportamento do sujeito individual, tenham escrito mais sobre as implicações clínicas de seu trabalho do que fizeram outros estudantes de Hull.

\section{Abordagens Comportamentais DA}

Psicopatologia como uma Reação Contra o "Modelo Médico"

As abordagens comportamentais aos problemas clínicos, acrescidas de sua ênfase em aplicar princípios de aprendizagem, também se opuseram ao uso da epistemologia da vida mental e do "modelo médico", um legado da prática médica de Freud com pacientes que se queixavam de dificuldades somáticas, tais como anestesias ou paralisias. Outros impulsos para definir neurose como patologia médica, originaram-se no esquema conceitual do seu treino neurológico que Freud adotou, tendo como modelo a falha da descarga nervosa, que causa variações somáticas dos impulsos não canalizados. $\mathrm{O}$ surgimento da psicologia do ego, com sua ênfase em uma gama de transações humanas mais amplas que a resolução dos conflitos, foi o desenvolvimento que abriu a psicoterapia para profissionais não médicos (Hartman, 1950). 
A oposição ao modelo médico não se restringiu aos psicólogos comportamentais, mas tomou a forma de grupos de sensibilidade, terapia não diretiva, biofeedback, treino de assertividade, métodos de grito primal, terapia emotivo racional e muitas outras. É tentador pensar na terapia comportamental cognitiva (Mahoney, 1977) como outro exemplo de oposição ao modelo médico, mesmo que em outros aspectos a proposta seja semelhante à de Freud. A semelhança entre as cogniçôes como o dado principal, e a afirmação de Freud de que ele lidava com a representação mental da experiência atual, coloca a teoria cognitiva mais perto da estrutura teórica da psicologia psicodinâmica que do comportamentalismo. Todas essas abordagens da psicoterapia são denominadas de comportamentais, não no sentido de que sejam conduzidas pelos princípios de aprendizagem e pela descrição objetiva do comportamento, mas porque elas rejeitam as afirmações da teoria freudiana a respeito do lugar central da resolução do conflito, que é ligado com a epistemologia freudiana da descarga motora.

Os Princípios de Aprendizagem e as Ciências Naturais como Referencial para Esclarecer a Prática Clínica

A aplicação dos princípios comportamentais sob o rótulo de terapia comportamental e modificação do comportamento contrasta com o emprego mais amplo do comportamentalismo, como um conceito científico natural, da natureza humana.

Inicialmente, por meio do trabalho pioneiro de Eysenck (1957) e de Wolpe (1958), as implicações dos escritos de Pavlov e Watson encontraram sua expressão na prática clínica vigente, como terapia comportamental. Como é inevitável na prática clínica, é difícil dizer quanto da terapia é guiada pela teoria orientadora e quanto pela interação e descoberta com o paciente. Os terapeutas estão reconhecendo cada vez mais a importância da habilidade clínica, na interação com o paciente, bem como a necessidade de ajustamento contínuo do procedimento clínico. De modo semelhante, na prática da modificação do comportamento Azrin (1977) vem salientando a importância de que os métodos clínicos se desenvolvam naturalmente e a importância das interações nas quais as mudanças no comportamento do paciente modelam o procedimento clínico do terapeuta. As implicações dessas tendências são uma contínua separação das tarefas da terapia comportamental e da psicologia comportamental. Os procedimentos clínicos estão se tornando orientados pela prática e pela experiência, talvez até mesmo adotando práticas das terapias convencionais. A terapia comportamental e a modificação do comportamento parecem estar se orientando mais pelos procedimentos práticos descobertos no campo.

Qual é, então, a relevância e a aplicabilidade de uma ciência do comportamento? Ela não se encontra em posição de descobrir os tipos de fenômenos complexos que os escritores, comentaristas sociais, filósofos e clínicos descrevem. Uma importante contribuição da uma psicologia comportamental é uma linguagem sobre a conduta humana, uma língua franca que seja uma alternativa à linguagem comum e à epistemologia mentalista da psicologia e da filosofia psicodinâmicas. Os clínicos experientes parecem ser capazes de se comunicarem eficientemente uns com os outros, e há 
freqüentemente acordo de que alguma coisa relevante, substantiva, está sendo comunicada quando um clínico experiente está falando. Mas freqüentemente é difícil saber em detalhes qual parte da terapia resulta em beneficio para o paciente. Na medida em que é possível descrever o que acontece, uma transmissão eficaz parece ocorrer entre pessoas que já sabem bastante daquilo que está sendo dito.

A linguagem comportamental tem a mesma vantagem para o trabalho clínico que a fisiologia tem para a medicina. $\mathrm{O}$ reforçamento, como a conseqüência imediata de um desempenho, é o alicerce da linguagem cientifica sobre o comportamento porque nos permite observar os detalhes dos componentes de uma atividade complexa em acréscimo ao seu funcionamento mais amplo. $\mathrm{O}$ principio básico de uma descrição comportamental é a separação da conduta humana, no ato em si, e a mudança que produz no ambiente, se essa mudança é no ambiente externo, dentro do indivíduo, ou em outra pessoa. Muitos clínicos reclamam que descrever em detalhes um ato complexo retira dele a qualidade essencialmente humana - e há razões para compartilhar essa preocupação. A minúcia de detalhes do experimento e a visão de conjunto de um praticante ilustram bem como a ciência e a prática se complementam. Um dos lados é ilustrado pela metáfora da pessoa com doutorado como aquela que sabe mais e mais sobre menos e menos, e de outro lado pelo praticante, como a fonte de conhecimento adquirido nas interaçôes diárias com os problemas da existência humana. É importante olhar, para além de uma linguagem particular clínica, coloquial ou mentalista, para a observação do paciente que deu margem à fala do clínico. É razoável supor que o clínico eficiente, levado a falar, viu alguma coisa importante. O psicólogo experimental requer a colaboração do clínico para saber quais são as experiências humanas importantes a serem formuladas cientificamente e quais de suas dimensōes são particularmente salientes. De outra maneira, como poderiam os cientistas naturais saber quais espécimes colocar sob o microscópio? Um sentido de controle é ilustrado quando o alimento é empregado para condicionar comportamento, como no experimento com pombos descrito previamente. Outro sentido de controle é a análise funcional, depois do fato, que relaciona o que aconteceu com as variáveis das quais o fato é função. É nesse último sentido que a análise funcional do comportamento operante pode servir como uma linguagem para converter o conhecimento encoberto derivado da experiência em termos objetivos e possibilitar que as práticas sejam refinadas pela experiência e comunicadas. Uma função da teoria da aprendizagem tem sido analisar vários modelos de terapia.

\section{Análise Psicológica da Terapia Psicodinâmica}

Desde a publicação do texto sobre psiquiatria de Masserman (1943), no qual ele tentou relacionar a patologia humana aos experimentos com animais em laboratório, tem havido um constante progresso dos teóricos que tentam estabelecer uma ponte conceitual entre a psicologia experimental e a clínica, no sentido de uma análise funcional do fenômeno. O livro pioneiro de Dollard e Miller (1950) Personalidade e psicopatologia foi uma das primeiras tentativas explícitas de aplicar, de uma maneira conceitual ampla, princípios de aprendizagem à psicoterapia. Eles seguiram a direção apontada por Watson, de que os princípios de aprendizagem poderiam conduzir todo o intercâmbio pessoal com o ambiente e esclarecer como padrões anormais emergem e 
como as mudanças no ambiente poderiam ser realizadas na terapia, para alterar os padrôes individuais de comportamento, para outros padrōes que seriam mais efetivos para manter seu comportamento nas condiçôes atuais. Diferente de Watson e das terapias comportamentais que seguiram a direção de Wolpe (1958), Dollard e Miller aceitaram a terapia psicodinâmica como um empreendimento prático e utilizaram princípios da aprendizagem para tornar a teoria e a prática comunicáveis. Como aqueles que tentaram anteriormente aplicar a ciência à prática, eles assumiram que padrões patológicos de comportamento foram aprendidos, como os normais, e que toda terapia influencia o comportamento através dos processos que descrevem como a aprendizagem ocorre. Dollard e Miller reconciliaram duas tradições. Primeiramente existia a psicanálise como um modelo influente de tratamento e a esquematização teórica das causas da psicopatologia. Como a teoria $\mathrm{da}$ aprendizagem, a psicanálise buscava as causas do comportamento anormal no inicio da história pessoal e social da criança. Dollard e Miller aplicaram as tradições de Pavlov, Thorndike, Hull e da aprendizagem social como uma tentativa de trazer a conduta patológica, revelada por Freud, para a visão de eventos naturais que podem ser descritos cientificamente. $\mathrm{O}$ pressuposto subjacente das duas perspectivas - a psicodinâmica e a comportamental - era que os fenômenos obedecem a leis estáveis.

Wachtel (1977), um psicanalista que também sofreu a influência de Dollard e Miller, continuou uma empreitada semelhante, embora seu livro, Psicanálise e terapia comportamental, tenha enfatizado informações da prática clínica que os princípios de aprendizagem deveriam, em alguns casos, contribuir para esclarecer. Wachtel, de sua visão privilegiada como terapeuta, foi capaz de descrever o comportamento do paciente e do terapeuta em mais detalhes do que normalmente se encontra, tanto em casos clínicos como em escritos comportamentais. Sua apresentação dos principais temas da teoria e da prática psicodinâmica beneficiou-se das relaçôes que ele encontrou entre a teoria comportamental, principalmente na abordagem de Dollard e Miller, e algumas das práticas da terapia comportamental. A visão de Wachtel da teoria psicodinâmica pode servir como um início para os psicólogos de orientação comportamental que gostariam de pensar sobre o fenômeno comportamentalmente, como Miller e Dollard o fizeram.

\section{Condicionamento Operante}

A abordagem do condicionamento operante para uma concepção da conduta humana pode ser representada por dois livros. O primeiro é o livro introdutório, clássico, de Keller e Schoenfeld (1950), que se inicia com a explicação dos princípios de aprendizagem, principalmente com animais, e termina com capítulos sobre o comportamento emocional e social na situação natural. O segundo é o livro Ciência e comportamento humano de Skinner (1953), que formula as principais dimensões da vida humana, pessoal e social, em uma perspectiva de princípios operantes. Como a aplicação da teoria de aprendizagem de Hull por Dollard e Miller à prática psicanalítica, Keller e Schoenfeld e Skinner usaram os princípios de aprendizagem para esclarecer o conhecimento do comportamento humano adquirido em outras fontes. Keller e Schoenfeld 
salientaram as observaçôes feitas pelas outras especialidades psicológicas, diferentes do condicionamento operante, enquanto Skinner explicou o controle comportamental envolvido nas observações rotineiras das agências humanas, como a lei, o governo, a psicoterapia e a religião, e em comportamentos complexos como autocontrole, eventos privados, e causação múltipla de repertórios. Essa visão panorâmica que Skinner apresentou, sobre grandes áreas de controle comportamental, serviu pra delinear os tipos de variáveis independentes que deveriam ser examinadas e os dados empíricos que deveriam ser observados. O capítulo sobre autocontrole, em Ciência e comportamento humano, por exemplo, serviu com um paradigma para Ferster (1962) trabalhar com o controle alimentar, o que, em contrapartida, estimulou uma série de aplicações à pesquisa empírica. A análise funcional do repertório de pessoas depressivas (Ferster, 1972) representa exemplo semelhante do emprego do paradigma básico, por propor-se a analisar funcionalmente os comportamentos componentes através do processo básico do comportamento operante. A análise funcional da depressão representa uma mudança no emprego dos princípios do condicionamento operante das técnicas de tratamento para seu emprego complementar com observações clínicas. A discussão da depressão começou assim:

A primeira tarefa de uma análise comportamental é definir o comportamento objetivamente, dando ênfase a classes funcionais (genéricas) de desempenhos que estejam de acordo com fatos que prevalecem na clinica, cujos componentes comportamentais possam ser observados, classificados e contados. Então é possível descobrir, pela aplicação dos princípios comportamentais, o tipo de circunstâncias que permitem aumentar ou diminuir a freqüência de certos tipos de atuação. Finalmente, um relato objetivo do fenômeno da depressão pode oferecer-nos um esquema para a experimentação que nos permita medir de maneira válida fenômenos clínicos complexos. Um relato objetivo a respeito da relação funcional entre o comportamento de um paciente e suas conseqüências no ambiente físico e social permitirá identificar itens eficazes de um procedimento terapêutico que possam ser aplicados seletivamente e com maior freqüência. (p.85, destaque acrescentado).

O mesmo paradigma é representado pela descrição do repertório da criança autista e seu desenvolvimento no ambiente natural (Ferster, 1967a). Apesar do grande número de experimentos tentando ampliar o repertório de crianças autistas que esse relato estimulou, é importante notar que os experimentos iniciais - demonstrando o sucesso da modificação no laboratório, do repertório de uma criança autista com reforçadores arbitrários, como alimento ou fichas - foram apresentados como uma força tarefa. O repertório comportamental desenvolvido por essas crianças, embora não tão complexos como aqueles envolvidos em um repertório social normal, foram utilizados para indicar a existência de um processo normal em um nível básico. A discussão do experimento concluiu: Nós não consideramos essas técnicas como tentativas de reabilitação, mas como uma análise experimental dos repertórios atuais e potenciais dessas crianças. Se for provado que é possível desenvolver e ampliar repertórios comportamentais significativos na sala experimental, então isso indicaria a 
possibilidade de que o mesmo potencial para modificação comportamental exista no meio social, se as condiçôes adequadas puderem ser produzidas. (p.97).

Recomendações para terapias específicas estão praticamente ausentes nas publicações de Skinner, apesar de seu apoio para esse modelo de tratamento. Skinner teve experiência própria somente no campo da educação, para o qual ele sugeriu métodos específicos de prática (Skinner, 1968). No entanto, ele escreveu sobre sistemas de classificação da prática existente, como em Ciência e Comportamento humano.

A ênfase da psicologia operante no repertório positivamente reforçado. Uma importante contribuição do condicionamento operante para a terapia clínica é a ênfase no desenvolvimento e manutenção de um repertório global. Até certo ponto, essa ênfase parece ser um resultado natural do viés instrucional da abordagem operante; e em parte é um subproduto da experiência, com o controle técnico, em a filigrana, do comportamento, que foi discutido anteriormente. $\mathrm{O}$ grande impacto emocional de Walden Two (1948) em tantos de seus leitores parece derivar de sua promessa de que toda a sociedade pode ser reforçada positivamente e acentuar a capacidade de todos os seus membros. Pavlov, Masserman e Miller e Dollard estiveram preocupados, em suas aplicações da pesquisa do laboratório aos problemas humanos, com o efeito destrutivo das experiências aversivas. No entanto, antes que Skinner abrisse a possibilidade do estudo técnico do reforçamento positivo no sujeito individual, existiam poucas maneiras de estudar a modelagem e a manutenção do repertório subjacente, cuja destruição pelo impacto da estímulação aversiva era a razão de preocupação. Havia não somente a possibilidade de que alguns prejuízos fossem o resultado de um repertório subjacente fraco, mas começou a surgir também a noção de que muitos repertórios importantes podiam estar ausentes porque o indivíduo nunca encontrou a experiência necessária em seu desenvolvimento - essencialmente uma lacuna de desenvolvimento. Embora Hull tenha lidado bastante com esse assunto, especialmente na discussão da "força do hábito", a ênfase em construtos hipotéticos inferidos e em experimentos que testavam hipóteses estatisticamente, sem tratar diretamente com o processo comportamental do indivíduo, enfraquecia o impacto de seu trabalho em assuntos clínicos. Vários daqueles para os quais Walden Two foi uma visão de uma nova sociedade, que poderia se tornar possível se os princípios de reforçamento positivo fossem amplamente aplicados aos problemas sociais, tinham a experiência de modelar e manter solidamente o comportamento de um pombo individual. Eles tinham tido a oportunidade de observar em primeira mão, ou por ler um registro acumulado, conhecimentos de um processo comportamental básico, como os estudos de O Comportamento dos organismos (Skinner, 1938) e os de Estes (1944).

A ênfase da psicologia operante no repertório atual como um produto da interação de uma pessoa com o ambiente físico e social tem um paralelo na história da psicologia psicodinâmica. A formulação de Freud salientava o domínio da perturbação dos principais componentes do repertório socialmente eficaz como um subproduto dos conflitos que eles engendravam. A terapia comportamental tem a mesma crença da visão 
inicial de Freud quando procurava remover os resíduos destrutivos de episódios traumáticos passados. As formulações psicodinâmicas mais recentes da psicologia do ego (Hartmann, 1950) salientaram uma esfera de desenvolvimento comportamental que podia agir independente dos impulsos biológicos e instintivos e dos conflitos que produziam. As formulações dos psicólogos do ego são consistentes com os processos que emergem da interação com o ambiente por meio dos processos básicos de reforçamento positivo.

\section{Análise Técnica Do Comportamento: Uma}

Maneira De Descrever Uma Interação

Terapêutica Complexa, De Forma Objetiva

\section{Comunicável E Em Detalhes}

A principal contribuição dos princípios do condicionamento operante é a precisão que pode ser alcançada na descrição dos eventos naturais que estão ocorrendo. Se a análise é um complemento da prática clínica, será então necessário contribuir para a observação e descrição do fenômeno clínico como ele ocorre em toda sua complexidade, no ambiente natural. Keehn e Webster (1969) fizeram a mesma distinção quando diferenciaram entre a terapia comportamental e a modificação de comportamento. Eles definiram a tarefa da análise comportamental (modificação) como uma maneira de entender como o comportamento é adquirido e alterado, e por isso aplicável aos objetivos da psicodinâmica como também da terapia comportamental. Um trabalho de Ferster (1967b) descrevendo os detalhes das interações de uma terapeuta experiente com uma criança autista, exemplifica como uma descrição objetiva no nível do desempenho com reforçadores imediatos contribui para a comunicabilidade e o refinamento da terapia. É importante salientar que as descrições eram da filigrana dos desempenhos da terapeuta e da criança e que a significância funcional da interação forneceu um quadro que complementava as descriçōes objetivas dos eventos imediatos.

Consistente com esse esforço colaborativo, a terapeuta e o experimentador apresentaram contribuiçóes e obtiveram ganhos. O experimentador aprendeu sobre as maneiras engenhosas pelas quais a terapeuta influenciava a criança. Em acréscimo à análise funcional das interaçôes por meio de princípios do comportamento bem conhecidos, emergiu um conteúdo que só poderia ser descoberto a partir da experiência, da habidade, e do inesperado vivenciados pela terapeuta e pelo paciente enquanto modelavam, por reforçamento diferencial, seus respectivos repertórios. $\mathrm{Da}$ perspectiva da terapeuta, a descrição comportamental da terapia permitiu que pequenos componentes dela se tornassem visíveis e comunicados em detalhe. A terapeuta, descrevendo a maneira como a análise do comportamento influenciou seu trabalho, relatou que agora ela pode explicar pequenos procedimentos passo a passo de modo que sua terapia ficava menos intuitiva e misteriosa. Como resultado disso, ela estava mais atenta para os detalhes dos eventos que tornavam eficiente o seu trabalho com as crianças e podia refiná-los, torná-los mais intensivos, e ensinar a outras pessoas habilidades semelhantes. Falando de sua experiência com a análise do comportamento, ela disse: "Sou capaz de ver os minúsculos pequenos passos e explicar muito melhor o que estou fazendo com a criança, e assim, a mágica está fora de Linwood - o que penso ser maravilhoso" (Ferster, 1976b, p.149). 
ReforÇamento Arbitrário e Natural e a Natureza Genérica do Comportamento OpERANTE

A distinção entre reforçamento arbitrário e natural (Ferster, 1967a, 1972a, 1974) referese a uma definição genérica do comportamento operante (Skinner, 1938; Findley, 1962) e consiste em um conceito crucial para a aplicação dos princípios comportamentais às modificações comportamentais que ocorrem na prática clínica. Resumindo, os procedimentos terapêuticos são arbitrários quando os comportamentos que eles reforçam são operantes diferentes daqueles da vida diária do paciente e nos quais incidem os problemas clínicos.

A análise de um exemplo relativamente simples do comportamento animal ilustra o princípio de que o desempenho operante é uma classe de atividades definida não por sua topografia, mas pela alteração no ambiente (reforçador) que, em contrapartida, aumenta sua freqüência. Assim, o som do alimentador que funciona quando o rato pressiona a barra aumenta a freqüência daqueles movimentos que deslocam a barra o suficiente para acionar o mecanismo que disponibiliza o alimento. Há uma conexão natural entre os movimentos do rato que aumentam de freqüência, as propriedades físicas da barra e o dispositivo elétrico que ela fecha. Porque o reforçador aumenta a freqüência dos desempenhos que ele segue, é possível descrever a pressão à barra como um tipo de comportamento que fecha o circuito elétrico, mais do que pela topografia do movimento. Existe uma relação semelhante entre o desempenho e o reforçador quando viramos o volante ou pressionamos o freio do automóvel. A topografia dos movimentos da mão e do pé que são reforçados é determinada pela mudança na direção do carro ou sua desaceleração. $\mathrm{O}$ desempenho e seu resultado constituem uma unidade comportamental integral, na qual um define o outro. A manutenção de tais formas de comportamento é virtualmente automática e tão estável quanto a relação natural do desempenho e as mudanças no ambiente que o mantém.

Há inúmeros exemplos desses desempenhos reforçados pela conexão física natural com as mudanças que eles produzem no ambiente. Os movimentos necessários para andar de bicicleta são reforçados pelas mudanças produzidas no balanceamento do ciclista com a gravidade; os movimentos de uma chave de fenda são modelados pela sua posição na ranhura do parafuso; os movimentos iniciais de "vestir o casaco" são reforçados pela posição do braço na manga; os movimentos de despejar água são reforçados pelo cair água no copo; os movimentos da pele do pescoço e do corpo da foca são reforçados pelo balanço da bola no nariz da foca; a magnitude do fechar e abrir os olhos é controlada pela intensidade da luz que bate nos olhos; e o movimento da pena sobre o papel é reforçado pelos formatos dos caracteres que aparecem e pela sua correspondência com as práticas normais da comunidade verbal da pessoa que usa a caneta. Em todos esses casos há uma primorosa interação entre o desempenho e as mudanças no ambiente que são fisicamente conectadas a ele. A unidade comportamental é estável e precisa e é mantida por tanto tempo quanto as leis físicas continuarem atuando. Os efeitos deletérios do desenho no espelho, as tentativas de escrever de olhos vendados, de falar sem ouvir os sons, ilustram o que acontece sem uma conexão natural, genérica, entre o desempenho e seu reforçador. 
Os contrastes e alternativas para esses reforçamentos genéricos são virtualmente impensáveis. Não há uma maneira prática de que o reforçamento com alimento possa reforçar as nuances da escrita, mesmo se aplicado como um reforçador condicionado antecedente. É difícil conceber como as nuances dos movimentos da musculatura vocal possam ser reforçados por outra coisa que a conexão genérica fina resultante dos padrōes auditivos. Por essa razão, muitas tentativas de reforçamento arbitrário ocorrem depois de um encadeamento comportamental no qual esses exemplos são os primeiros deles. Mas as mesmas propriedades do reforçamento genérico operam mesmo quando essas atividades são os comportamentos iniciais em uma cadeia, contribuindo para outro efeito prático ou para as interações sociais. Considere, por exemplo, o comportamento de colocar o casaco de uma criança, reforçado por alimento. É claro que o alimento pode ser empregado para ensinar a criança a colocar o casaco utilizando aproximaçóes sucessivas do ato completo. O casaco é mantido na posição adequada e algum reforçador condicionado, derivado de alimento, pode reforçar precisamente as aproximações requeridas. Nesse estágio, a posição das mãos da criança na manga do casaco pode ser um reforçador para uma cadeia de comportamentos que conduza a alimento ou fichas, como a pressão à barra para o rato pode ser reforçador para olhar a posição da barra e manipular manualmente o dispensador de alimento quando ele se move na distância requerida. O problema não é se um reforçador ou outro pode reforçar diferencialmente o comportamento de colocar o casaco, mas os efeitos colaterais indesejáveis e quanta sobreposição há, em colocar o casaco, por alimento e colocá-lo, para ficar aquecido.
Tecnicamente, os dois casos são cadeias de desempenhos, nos quais os primeiros componentes são reforçados, pela posição do casaco no braço da criança. O segundo componente é tanto a ficha, no caso arbitrário, como o alivio do frio, no caso natural.

\section{Reforçamento Natural}

O diagrama da Figura 1 mostra o repertório da criança e do terapeuta interagindo entre si quando o reforçamento é natural. Todos os reforçadores que mantém o vestir estão na parte inferior do diagrama. Colocar o casaco é o elo inicial da cadeia, a segunda parte é um operante negativo - esquiva das temperaturas frias. A tarefa do terapeuta é inteiramente instrucional, provendo um apoio colateral que é diminuído à medida que a criança realiza mais e mais o vestir. No início, o terapeuta coloca o casaco na criança, com exceção da última manga. Ele coloca o braço da criança na entrada da manga e assim, com uma simples extensão do seu braço, a criança completa o vestir. Com o casaco, a criança pode ir para fora sem sentir frio. Com aproximações sucessivas do repertório final, o terapeuta contribui progressivamente menos, até que o vestir esteja completo, sem apoio, e a intervenção do terapeuta não é mais necessária. A intervenção é educacional porque o terapeuta na realidade não reforça o comportamento da criança, mas facilita o reforçamento que ocorre quando a criança vai para fora no frio. Ele provê apoio colateral que amplia o comportamento da criança para permitir que ele seja reforçado naturalmente, em outros lugares. Em uma linguagem mais geral, podemos dizer que o terapeuta facilita o comportamento que, quando ocorre, terá suporte independente dele, pela relação inerente entre o ar frio, a temperatura da pele $\mathrm{e}$ 
estar usando o casaco. Exemplos semelhantes podem ser prontamente construídos com os utensílios de comer, montar e desmontar de um cavalinho de balanço, beber de um copo, colocar os sapatos, ou subir os degraus de escada de um local da casa para outro.

\section{Reforçamento Arbitrário}

A Figura 2 é o diagrama ilustrando o reforçamento arbitrário do mesmo desempenho. Vestir-se é reforçado em um encadeamento, como no exemplo do reforçamento natural apresentado anteriormente, mas com a diferença que o elo final da cadeia é "comer biscoitos" e não ficar aquecido. Para manter a atividade de vestir-se, o terapeuta necessita continuar a reforçar com biscoitos em contraste com o caso natural, quando o terapeuta tem apenas que providenciar apoio colateral para mediar temporariamente suas interaçôes com o tempo frio.

\section{Aspectos Sociais Da Interação Terapêutica}

A considerável complicação do procedimento de reforçamento arbitrário decorre da natureza social da interação terapêutica. A terapia é uma interação na qual o reforçamento do comportamento do terapeuta, pelos desempenhos que se desenvolvem no repertório da criança, é um componente tão importante quanto o desempenho da criança reforçado pelas contingências ou instruçôes fornecidas pelo terapeuta. É nessas interações, nas quais o terapeuta e a criança liberam os reforçadores para as participações um do outro, que uma análise da relação genérica entre os desempenhos e seus reforçadores pode ter uma ampla e prática importância para os resultados da terapia. Os desempenhos do terapeuta são reforçados porque induzem a criança a colocar seu casaco. Os desempenhos da criança, com o casaco, são reforçados pelo alimento ou pelas fichas que o terapeuta lhe dá. Se a criança come ou não, não é importante, em si mesmo, para o terapeuta; e se a criança põe seu casaco, em si mesmo, não é importante para a criança. $\mathrm{O}$ terapeuta poderia parar de dar alimento se a criança se vestisse por outras razóes, e a criança poderia parar de vestir-se se recebesse alimento sem fazê-lo.

Uma conseqüência do controle interpessoal do reforçamento arbitrário é a filigrana, a correspondência o ponto a ponto do desempenho da criança com a reatividade do terapeuta, mais do que os efeitos de ficar aquecido lá fora. Enquanto o desenvolvimento de um repertório interativo entre a criança e outras pessoas pode ser um dos mais importantes objetivos da psicoterapia, essas interações [arbitrárias] têm subprodutos inerentemente indesejáveis que, a longo prazo, serão anti-terapêuticos. A desvantagem do reforçamento arbitrário vai além

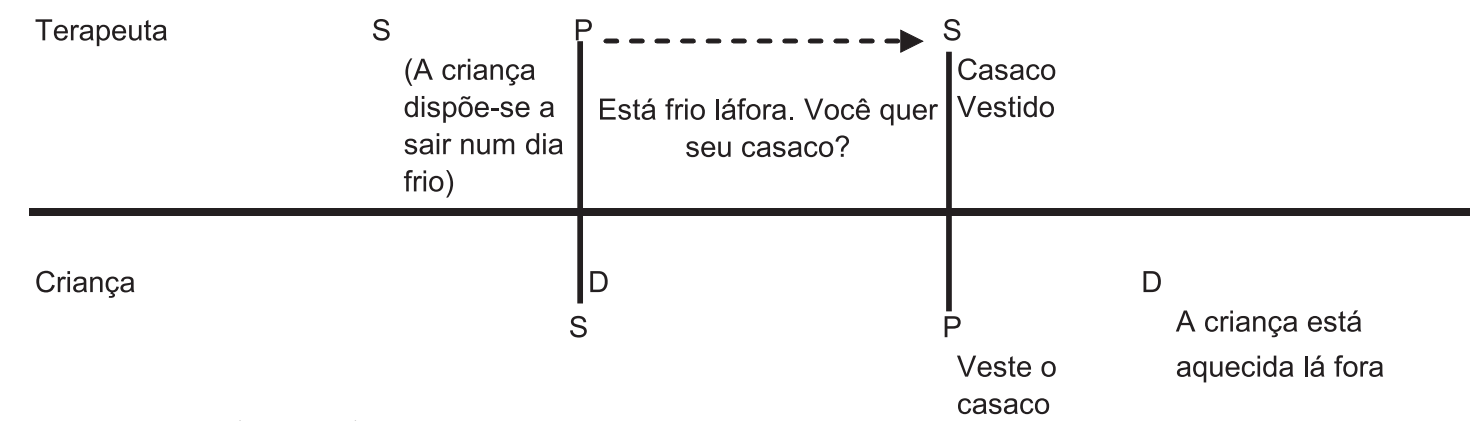

Figura 1. Controle Natural 
Verbal

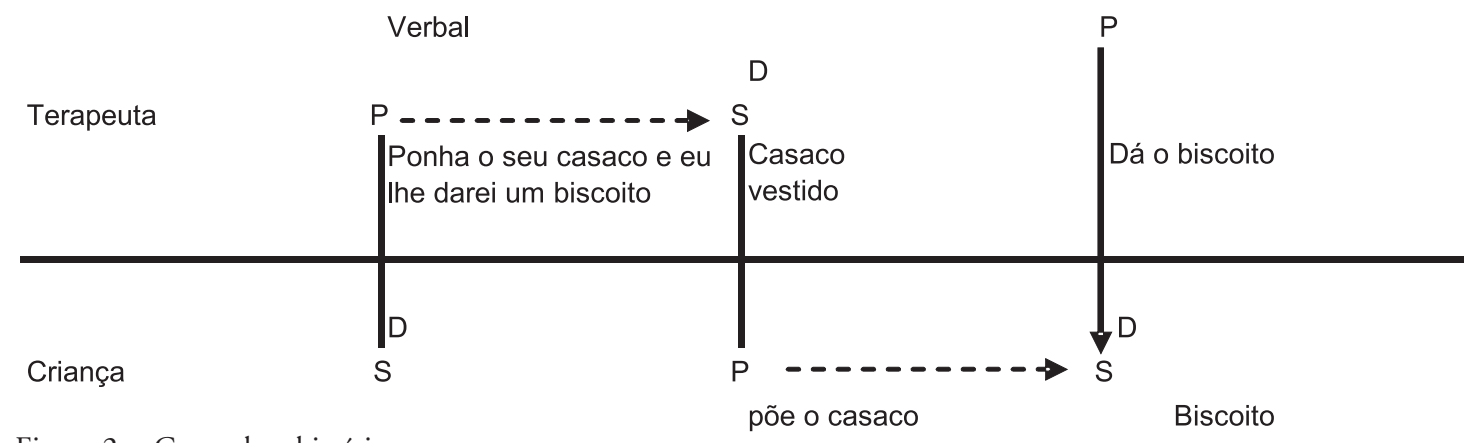

Figura 2 - Controle arbitrário

da ausência de uma conexão genérica entre usar um casaco e a experiência da criança lá fora, no ar frio, que ocorre quando a comida substitui o calor do casaco.

\section{A Luta pelo Poder}

Um desastroso subproduto do controle arbitrário é o contra-controle que pode ocorrer quando o terapeuta tenta aumentar a freqüência de algum comportamento que o cliente não está disposto a emitir. A propriedade específica do reforçamento arbitrário que conduz a uma disputa entre os participantes é salientada no diagrama de interações arbitrárias mostrado na Figura 2. O reforçamento da atividade de cada participante depende do outro. A criança, que foi interrompida em sua forma costumeira de obter alimento pode implicar ou obstruir o trabalho do terapeuta, retendo o reforçador do terapeuta - a cumplicidade com os objetivos da terapia do reforçamento. Essa propriedade da interação é especialmente proeminente e crítica quando a criança, por outras razões, tende a agir agressivamente com o terapeuta. A dificuldade é ainda maior porque a atividade agressiva da criança com o terapeuta pode ser, em si mesma uma importante questão para a terapia. Esses conflitos entre a criança e o terapeuta podem ter uma escalada, porque a criança pode reforçar diferencialmente formas extremas de controle ao deixar de apresentar o comportamento que o terapeuta está tentando aumentar de freqüência. Quando o terapeuta intensifica o desafio aplicando mais privação e impedimentos, a agressividade da criança geralmente aumenta, requerendo por sua vez, maiores níveis de controle aversivo pelo terapeuta. No final a interação pode ser descrita como "uma luta de vontades". O resultado é paralelo ao processo que ocorre quando a criança apoquenta seus pais, que diferencialmente reforçam caprichos e provocaçōes concordando com as exigências da criança, ou atendendo somente quando as exigências tornam-se suficientemente aversivas para aumentar a freqüência de um desempenho que terminará ou evitará o capricho. A primitividade e o paradoxo desses desafios é que os pais, intencionalmente ou não, reforçam o comportamento da criança que é o mais aversivo para ele ou ela, até que controles extremamente aversivos sejam praticados pelos dois lados.

Embora essas lutas de poder, como descritas clinicamente, sejam mais proeminentes quando incluem controle pelo estímulo aversivo, esse fato é em si mesmo a característica que define o controle arbitrário. O estímulo aversivo pode aumentar a freqüência do comportamento genericamente e naturalmente como, por exemplo, quando 
protegemos os olhos da intensa luz solar, colocamos os dedos no ouvido para atenuar o barulho alto, colocamos ou retirarmos roupas para o frio ou calor, e tapamos as narinas para evitar o odor insalubre. A relação entre esses comportamentos e o controle aversivo que eles atenuam são estáveis e totalmente previsíveis, em contraste com o controle interpessoal, onde um participante influencia o comportamento do outro com estímulos aversivos para aumentar a freqüência de algum desempenho relevante para o reforçamento de seu próprio repertório. Inversamente, eventos que pelo nome podem funcionar como reforçadores positivos podem se tornar um componente no controle arbitrário, como por exemplo, o emprego de alimento, discutido nas seções precedentes, para reforçar o vestir ou o falar. Esses procedimentos têm as características do controle arbitrário porque a maneira costumeira natural com pela qual a criança é alimentada é descontinuada ou bloqueada, permitindo assim ao terapeuta uma ampla possibilidade de arranjar qualquer contingência entre comer e o desempenho desejado. É a liberdade de ação do terapeuta, quando ele ou ela ajusta as contingências reforçadoras com o propósito de criar o repertório que busca desenvolver, que conduz ao relacionamento competitivo no qual cada parte pode exercer controle aversivo sobre a outra. Dessa forma, o repertório que resulta se desvia da maneira natural com que o ambiente alimenta a criança, para um outro que advém da reatividade de um terapeuta em particular e do procedimento reforçador específico que o terapeuta aplica.

\section{Alimento como um Reforçador Natural}

Se a comida é genericamente relacionada com o desempenho que ela reforça, ela pode também ser um reforçador natural. Por exemplo, se é dada à criança alguma responsabilidade por preparar sua refeição, de acordo com seu repertório existente e em aproximações sucessivas para formas mais complexas, o desenvolvimento comportamental resultante será semelhante ao reforçamento de colocar o casaco que descrevemos anteriormente.

\section{Reforçamento Arbitrário como uma Transição}

É possível que o reforçamento arbitrário possa ser empregado na terapia como uma transição para a mesma topografia naturalmente reforçada. Infelizmente temos pouco conhecimento clínico sobre o processo pelo qual o reforçamento de uma topografia de comportamento mantida por um reforçador contribui para a sua manutenção por um reforçador inteiramente diferente em outra situação. Sabemos, no entanto, que o problema é facilmente evitado pelo emprego dos mesmos princípios comportamentais do reforçamento natural. Temos evidência de que tais reforçadores têm potencial para manter o comportamento tão fortemente como a comida, por exemplo, nos experimentos relatados por Creed e Ferster (1972) e Ferster e Hammer (1966), sem os efeitos perniciosos colaterais do controle arbitrário.

A estratégia para aplicar princípios comportamentais no ambiente natural é começar com algum comportamento do repertório do paciente e prover variáveis colaterais que permitirão reforçá-los em um ambiente ao qual o paciente normalmente tem acesso. Reforçadores potenciais para quase todo tipo de repertório existem em alguns ambientes. Pode ser possível construir um repertório prosseguindo em pequenos passos a partir de um desempenho que vem sendo mantido 
atualmente em uma parte do ambiente do paciente, para um desempenho ligeiramente mais complexo, que poderia ser reforçado em outra parte do ambiente, também acessível (Ferster, 1979). A tarefa consiste em arranjar apoio colateral para a capacidade que o paciente já tem e que pode trazê-la para uma forma que seja naturalmente reforçada por uma característica estável do seu ambiente. Neste caso, o apoio colateral pode ser gradualmente esvanecido para outro controle de estimulo (fading), de acordo com a capacidade do paciente, até que surja um repertório que seja reforçado sem a intervenção do terapeuta. Infelizmente, o aspecto de "inércia" de muitos tipos de déficits comportamentais complica esse remédio direto (Ferster, no prelo) embora o princípio básico ainda pareça aplicável.

\section{Dois Sentidos Do Controle}

Implícitos nas diferentes propriedades de reforçamento arbitrário e natural encontramse dois sentidos de controle que os procedimentos de reforçamento carregam. Um sentido é pejorativo, quando os comportamentos que podem ser aumentados de freqüência o são para beneficio do controlador, com menor atenção aos objetivos do controlado. O professor exige que o aluno fique quieto na classe; $\mathrm{o}$ atendente de enfermaria julga que os pacientes devam manter sua roupa limpa; o terapeuta comportamental acha que o paciente mudo deva falar. O outro sentido, mais de acordo com o reforçamento natural e com o emprego dos princípios comportamentais como um quadro descritivo, elucida a relação funcional entre a conduta do paciente e as variáveis das quais ela é função. Para o melhor ou o pior, todo o comportamento do paciente é controlado. O ponto principal é se uma relação clara do controle pode ser comunicada e para o beneficio de quem e por quais razōes o controle é exercido. O reforçamento arbitrário não é, evidentemente, limitado aos procedimentos de terapia comportamental.

O seguinte relato de Jeanne Simmons (Ferster, 1967a) trata do emprego de reforçamento natural na psicoterapia de um ponto de vista diferente daquele das terapias comportamentais.

E esta éa razão pela qual andamos atrás da criança. Ela sente sua proteção quando você anda atrás. Se você dá a ela a oportunidade de ir para qualquer direção, ela pode estar errada quando vai em uma ou outra direção. Apenas siga-a. Se ela tomar um caminho sem saída, pegue-a gentilmente e tragaa para o caminho principal. Mas nunca pense que você sabe a resposta, porque você está tratando com um indivíduo que pode querer ir por caminhos diferentes, que para ele podem ser os melhores. É por isso que me sinto mais confortável atrás das crianças, pois assim, posso ver para onde estão indo. (p.346).

Essas afirmações sobre os objetivos da terapia salientam a importância crucial do reforçamento natural, genericamente relacionado com o repertório existente da criança, mesmo quando a linguagem é a de um clínico totalmente envolvido nas interaçôes pessoais com as crianças. A afirmação do objetivo da terapia implica que ela se inicia com os comportamentos existentes no repertório da criança, mantidos pelos reforçadores atuais. Os procedimentos descrevem apoios colaterais do terapeuta, para o repertório da criança, que antecipa dificuldades que a criança pode encontrar e encoraja as partes mais eficazes da capacidade atual da criança (buscando a saúde 
da criança, ela diria). O mesmo tema é recorrente em outras fontes da literatura clínica (Searles, 1965; Glover, 1955; Rogers, 1965).

\section{O Papel Fundamental do Comportamento Verbal na Psicoterapia}

A psicodinâmica e outras terapias convencionais consistem em relatos principalmente das queixas sobre dificuldades na vida e a interação verbal com o terapeuta a respeito delas. Várias abordagens comportamentais também envolvem o cliente falando com o terapeuta, apesar do referencial teórico que salienta o comportamento observável que é passível de enumeração objetiva. A abordagem comportamental para autocontrole, delinqüência, e problemas sexuais começam com o relato de uma entrevista sobre as queixas do paciente e falas sobre elas, como na terapia de dessensibilização, ou instruções para o paciente para a realização de ações fora da sessão. A observação de que interações verbais predominam tanto no diagnóstico como na terapia tem grandes implicações sobre como uma ciência do comportamento humano pode prover suporte para o tratamento clínico. $\mathrm{O}$ primeiro passo nessa aventura é a explicação comportamental de como o terapeuta e o cliente alteram o comportamento um do outro no contexto imediato de sua interação. Depois disso, a empreitada pode voltar-se para explicar como o comportamento verbal que emerge como produto da terapia pode amenizar problemas na vida do paciente.

Dado que o ponto de partida da análise comportamental é a interação imediata entre o paciente e o terapeuta, é aconselhável iniciar com uma revisão geral de como o reforçamento verbal ocorre, antes de discutir o reforçamento da fala do paciente na entrevista terapêutica. $\mathrm{O}$ comportamento verbal, como comportamentos operantes mais simples, é definido pelos seus reforçadores, mais do que pelas topografias do desempenho. Sua topografia, os movimentos da boca, dos lábios, da língua e do diafragma, é muito complexa para ser reforçada por alguma coisa mais do que sua relação fina com o som que produz, de uma maneira análoga ao balanço da bola no nariz da foca ou o equilibrista na bicicleta. A reação do ouvinte é a contrapartida genérica do falante. No sentido de seu aspecto mais refinado e da imediaticidade, o comportamento verbal é reforçado pelo "falante como seu único ouvinte" que liga as práticas reforçadoras da comunidade verbal ampla. A questão do reforçamento arbitrário e natural é ainda mais crucial no comportamento verbal que nas formas não verbais. Propriedades do comportamento do terapeuta mantidas estáveis provêm as reações que sustentam e modelam a fala do paciente. Ou alternativamente, a fala do paciente reflete o controle pelos ouvintes anteriores, indutivamente. As partes dos dois repertórios que se interligam representam um reforçador que tem uma fina sintonia, igual à sensibilidade do terapeuta e ao seu treinamento como ouvinte. Um déficit em controle interpessoal é um obvio objetivo comportamental que pode ser desenvolvido através de reforçadores naturais inerentes à interação terapêutica. A reatividade diferencial do terapeuta, como um ouvinte treinado, tem o potencial de remediar aquelas partes da fala do paciente que são mais controladas por sua privação do que pelas circunstâncias nas quais ela pode ser reforçada. Especialmente relevantes para o reforçamento diferencial são as expectativas impraticáveis ou as exigências irreais feitas ao terapeuta. De outro lado, as 
reações que o paciente evoca no terapeuta são dados sobre seu repertório. O resíduo no repertório do terapeuta, também é verbal. $\mathrm{O}$ controle estreito entre o para falante-ouvinte, terapeuta-paciente, cria uma situação na qual os reforçadores são naturais, no sentido de que são mantidos por propriedades estáveis de ambos os repertórios.

\section{A Confusão entre os Eventos da Vida do Paciente e} o que Ele Diz Sobre Eles

Se a interação verbal entre o paciente e o terapeuta é observável e comportamentalmente objetiva, os eventos sobre os quais ambos falam, aqueles da vida do paciente em outro local, são inferências sujeitas a distorções e descriçôes incompletas, não importa quão objetivos sejam os termos. Se a descrição de eventos comuns está sujeita a distorções, então o relato do paciente de porque ele ou ela agem é ainda mais duvidosa. Frequentemente há uma frouxa correspondência entre, por exemplo, a descrição do paciente sobre o que levou a faltar a um compromisso ou a razão de porque certos tópicos são omitidos, e as variáveis independentes que podem eventualmente chegar a ser descobertas. A falha em diferenciar o que está sendo falado da própria fala é uma dificuldade técnica importante que pode ocorrer em qualquer terapia verbal, mas é mais visível nas terapias comportamentais do que em outras porque a linguagem comportamental amplia a discrepância.

Uma razão para a confusão entre os eventos da vida do paciente e a fala que ocorre em psicoterapia é que os reforçadores verbais são arbitrários em relação aos comportamentos relatados sobre a vida do paciente e vice-versa. A contrapartida genérica do comportamento do paciente na terapia são as influências sobre o terapeuta que está ouvindo e sobre o paciente como seu próprio ouvinte. A contrapartida genérica dos eventos em andamento na vida diária do paciente são as ocorrências do dia a dia. Obviamente, o que é dito sobre a vida do paciente influencia o que o paciente pode fazer em seguida, e viceversa, mas a conexão é um repertório que precisa ser examinado separadamente.

Uma Análise dos Comportamentos que Ocorrem nas Interaçóes Próximas entre o Paciente e o Terapeuta

O comportamento que ocorre na terapia é um dado objetivo no qual muitas atividades e seus reforçadores podem, pelo menos potencialmente, ser observadoS por ambas as partes. Talvez, porque estejamos acostumados a buscar para além dos eventos imediatos da interação terapêutica, sua natureza potencialmente objetiva e comportamental é desconsiderada.

1. O controle inicial da fala do paciente. Quando dizemos que o paciente "fala com um terapeuta", a implicação é que a fala do paciente é mantida pela maneira pela qual ele o influencia. Quando dizemos que o terapeuta escuta o paciente, os eventos imediatos são o controle do terapeuta pelo paciente. Contudo, ao começar, nenhuma das partes tem uma história de controle pela outra. Claramente, o controle sobre o paciente, no início, não é completamente especifico àquele terapeuta em particular. Se assim não fosse, seria pouco provável que o paciente falasse longamente, frequentemente com poucos comentários do terapeuta, durante a primeira entrevista. Muito de seu comportamento parece funcionar como um mando mágico como "Eu gostaria que parasse de chover", ou "Opa, estou com fome"; 
são todos queixas generalizadas que são extensões para além das circunstâncias normais nas quais poderia haver quaisquer expectativas realistas de que o ouvinte normal fornecesse alívio (Skinner, 1957, Cap. 3). Essas queixas generalizadas têm conexão com circunstâncias passadas onde ajuda semelhante tenha estado disponível. A situação de terapia, bem como os exemplos de mando mágico mencionados anteriormente, são diferentes das situações comuns onde ocorrem operantes negativamente reforçados. Nesses casos, o nível de privação do paciente-falante excedeu a história normal de controle pela audiência, causando a emissão da queixa ou pedido por alívio, apesar da falta de história com o terapeuta especifico. É por essa razão que as primeiras entrevistas são tecnicamente tão difíceis em psicoterapia.

O repertório inicial a partir do qual deve emergir a conexão entre as duas partes é uma fantasia à qual não é plausível que o ouvinte reaja fornecendo o alívio buscado. Contudo, é a partir deste repertório, o inicial, que o desenvolvimento comportamental deve emergir. Uma qualidade óbvia do repertório inicial do paciente é sua inércia. Uma parte considerável dele parece ser controlada pela privação, mais do que pela audiência que governa onde e quando pode ser reforçado. Um corolário desse repertório é uma falha em observar em detalhes e com algum distanciamento das privações pessoais, as características de outras pessoas em cujo repertório há reforçadores potenciais. Repertórios com essa propriedade de imobilidade são reminiscência de padrões alimentares infantis, quando o nível de privação esvaziava todo comportamento brincalhão e a atenção a qualquer outro evento além da refeição. Mesmo formas complexas de fala podem ser funcionalmente equivalentes à alimentação da a criança se os reforçadores que as mantém são controlados de perto por altos níveis de privação do falante, mais do que pelo reforçamento generalizado. Uma frase elegante ou um poema podem funcionar como uma queixa ou solicitação, apesar de sua topografia complexa. O terapeuta, como um ouvinte treinado que analisa funcionalmente a interação verbal com o paciente, está em posição de reagir diferencialmente a um paciente, dependendo da verdade do que esteja sendo dito.

\section{Reforçamento do comportamento verbal} pelo terapeuta-ouvinte. A mudança das reclamações generalizadas para desempenhos reforçados por seu efeito genérico sobre o terapeuta-ouvinte é, em si mesma, um exercício de análise do reforçamento generalizado. Mesmo que queixas e solicitações por ajuda possam requerer a participação do terapeutaouvinte, eles funcionam diferentemente da interação verbal que pode ocorrer posteriormente na terapia, quando a interação imediata com o terapeuta começa a manter a fala do paciente. O repertório inicial do paciente é relativamente insensível às reações do terapeuta, em grande parte porque é um operante negativamente reforçado, um mando é um jargão verbal, em grande parte sob o controle da privação do paciente e de estimulação aversiva. A frase final do terapeuta em Complexo de Portnoy de Phipip Roth, novela sobre psicanálise, "Agora podemos começar", depois de um livro inteiro de queixas solilóquias, ilustra a mesma mudança no controle funcional entre a fala do paciente e sua relação com o repertório do terapeuta. A mudança da queixa generalizada para o desempenho mediado pelo terapeuta é um exemplo da definição refinada de comportamento verbal discutida 
anteriormente (Skinner,1957, pp. 224-226) na qual a forma e as características do comportamento do falante (o paciente) são determinadas pela reatividade verbal, sem igual, do ouvinte (o terapeuta). A analogia com o exemplo da foca balançando a bola é com a pressão no nariz como reforçador, ao invés da comida. A definição refinada do comportamento verbal supõe o efeito imediato da interação entre duas pessoas, do mesmo modo como ocorre com uma luz no olho, a virada da cabeça, e como o conteúdo de uma resposta corresponde às variáveis que controlam a afirmação do paciente. $\mathrm{O}$ mesmo processo ocorre, claro, ainda com maior imediaticidade e sutileza quando o falante ouve a si próprio.

$\mathrm{Na}$ medida em que a interação com o terapeuta é semelhante àquela que acontece com outros, ela constitui um incremento na capacidade social. O contexto abrigado da entrevista terapêutica, particularmente a respeito do apoio colateral que o terapeuta provê, pode criar uma capacidade social que se estenderá para outras pessoas e situações. Os eventos comportamentais na situação terapêutica imediata fornecem uma oportunidade para interpretação e descrição porque elas são uma aproximação do tipo de observações que podem ser realizadas em outro lugar. De significação clínica equivalente é o comportamento de efetivamente relatar os fatos para o terapeuta. A fala do paciente "para o terapeuta” tem duas funçôes simultâneas. A primeira é um tato, geralmente bastante distorcido e impuro, sob o controle de fatos do momento ou da infância (ou de qualquer outro evento passado que o paciente esteja falando sobre); talvez seja algum resíduo intraverbal de um fato passado. Segundo, e mais importante, é o desempenho cuja forma foi modelada pelos falantes dos quais o paciente teve influência no passado. Se a reatividade latente do terapeuta é semelhante à dos indivíduos que mantiveram o comportamento do paciente no passado, o episódio verbal terá sucesso e será estável. $\mathrm{Na}$ medida em que o terapeuta não reage da mesma maneira que os ouvintes do paciente fizeram, há uma oportunidade, primeiro, para reforçamento diferencial, e segundo, para observação da discrepância entre o comportamento do paciente e o reforçamento do terapeuta.

Quando o paciente está contando ao terapeuta, por exemplo, sobre a sua infância, o efeito que é produzido no terapeuta, como um ouvinte, é a característica mais importante do comportamento verbal do que evento que ele descreve. O reforçador nesse episódio verbal é sutil e está no cerne da definiçãa de reforçamento verbal. A delicada interação entre duas pessoas, que ocorre quando alguém tenta explicar alguma coisa, ilustra o processo. Há um dar e receber quando falante e o ouvinte interagem entre si até que o ouvinte fale que ele entendeu e o falante não é mais inclinado a explicar porque o ouvinte pode agora, dizer o que foi explicado. Funcionalmente, a fala do paciente é um desempenho reforçado principalmente por "fazer o terapeuta entender" e só secundariamente um desempenho que descreve a vida passada do paciente. A vantagem dessa relação funcional entre terapeuta e paciente, ouvinte e falante, é que a interação reforça (e, portanto, aumenta a freqüência) de explicações e observações da vida do paciente. A habilidade do terapeuta em fazer uma análise funcional do comportamento emitido que ele está observando na situação imediata e o interesse do terapeuta nas observações do paciente dão, 
à reatividade verbal do terapeuta, uma vantagem única.

3. Ensinando o paciente a observar seu próprio comportamento e descrever suas interaçôes com o terapeuta. Os eventos imediatos da interação psicoterapêutica provêem oportunidades específicas para o terapeuta, como um ouvinte e observador treinado, dar dicas e reforçar as atividades verbais do paciente que são descritivas de suas experiências públicas e privadas. Quando o par terapêutico é uma díade na qual a reatividade de um reforça a atividade do outro, o resultado é um aumento do repertório verbal sob controle dos eventos imediatos que ocorrem. As reações diferenciais do terapeuta podem reforçar descrições das ocorrências atuais, falar sobre os eventos privados debaixo da pele e que o paciente pode não ter consciência, os eventos externos dos quais esses eventos privados são função e o comportamento de outros que interagem no processo. Embora falemos, coloquialmente, sobre como a paciente nota seu próprio comportamento, a realidade, comportamentalmente, é o reverso porque é a reação diferencial do terapeuta que reforça o comportamento verbal sob controle dos eventos privados, as ações e as influências encobertas prévias e as variáveis que controlam o comportamento do paciente. Essa atividade verbal aumentada emerge como tatos e comportamento intraverbal sob o controle de interaçôes entre o terapeuta e o paciente à medida que eles lidam com os eventos imediatos, que rodeiam sua tarefa comum. $\mathrm{O}$ terapeuta como um ouvinte treinado que está fazendo uma análise funcional da interação entre eles, pode trazer a atenção do paciente para um aspecto do comportamento, mais do que outro. $\mathrm{O}$ controle do paciente pelo terapeuta é que genericamente define o desempenho, incluindo o reforçador do qual é função, mais do que o conteúdo, a topografia, ou "o sentido superficial” do que o paciente está dizendo.

Um dos objetivos da psicoterapia, que a distinguem do procedimento educacional, é permitir ao paciente falar dos processos encobertos ao criar condições através das quais ele pode observar aspectos de sua conduta e de seus antecedentes funcionais que, de outra maneira, passariam despercebidos. Silêncios prolongados, conflitos sobre o agendamento de sessões e esquemas de pagamento, discrepâncias entre as exigências do paciente e a visão prática do tipo de ajuda possível, chegar tarde ou perder agendamentos, por exemplo, frequentemente ocorrem porque alguns fatos atuais são muito aversivos de se abordar. Uma vez que o terapeuta torna-se um ouvinte cuja atenção torna-se genericamente conectada à fala do paciente, surge a possibilidade de repertório verbal que pode conduzir o paciente a observar os múltiplos determinantes dos atrasos ou do silêncio e a falar sobre variáveis das quais são função. O controle discriminativo do comportamento humano é predominantemente verbal. De fato, muito do controle diferencial do comportamento humano pelo ambiente físico, bem como social, pode ocorrer somente verbalmente, principalmente com aqueles comportamentos que são sociais e verbais.

A dessensibilização do controle aversivo do comportamento verbal é outro produto potencial de qualquer entrevista ou procedimentos terapêuticos nos quais a fala do paciente sobre assuntos difíceis vai sendo ajustada à sua habilidade de tolerá-los. Como foi salientado na sessão anterior sobre terapia comportamental, um aumento na quantidade da atividade verbal contribuirá para muitas outras funçôes terapêuticas. 
Como o Comportamento Verbal com um Ouvinte Treinado Pode Inlfuenciar a Vida do Paciente em Outros Locais

Dado que os comportamentos que ocorrem na terapia são diferentes das atividades que ocorrem em outros ambientes, uma tarefa crucial da análise comportamental é descrever o processo pelo qual os dois repertórios se influenciam mutuamente. Se não houvesse uma grande discrepância entre o que de fato aconteceu com o paciente em sua vida diária e seu relato sobre o que acontece, não haveria, com toda probabilidade, um problema que exigisse terapia.

\section{O repertório interpessoal com o terapeuta.} A interação entre as duas partes é em si mesma um aumento do repertório e um modelo, para melhor ou pior, do que pode acontecer entre quaisquer duas pessoas. À medida que o paciente aprende a influenciar o terapeuta há elementos de seu repertório que podem influenciar por outras pessoas em outras situações. Na medida em que o paciente pode observar os detalhes da conduta do terapeuta, como ele ou ela a influenciaram e o processo reverso, o paciente faz progressos $\mathrm{n}$ a habilidade de fazer as mesmas observações em outros lugares. Se o paciente observa seu próprio aborrecimento e sonolência e aprende a buscar por antecedentes provocativos para essa evidência de sua ansiedade, há a possibilidade de que ele possa ser capaz de fazer uma busca semelhante em outras ocasióes em que ficar sonolento ou aborrecido. O terapeuta, como um observador treinado, que constantemente está fazendo análise funcional entre os eventos atuais na interação entre eles, está em posição análoga à do professor de violino que pode ajudar o estudante a ouvir nuances de tons que de início são audíveis para o professor mas não para o estudante. A condição necessária, no entanto, é que haja uma disposição significativa para tocar o violino de tal modo que as notas executadas possam ser examinadas.

2. O Repertório Verbal da Psicoterapia Aumenta a Observação. A habilidade do paciente em observar eventos em sua vida está intimamente ligada com sua habilidade de falar sobre eles, do mesmo modo que tocar alguma coisa, apontando ponto a ponto com o indicador, para o leitor iniciante, coloca o comportamento sob um controle mais sutil dos detalhes componentes, do que se o único movimento fosse o do globo ocular e seu foco. Uma vantagem educacional de um repertório verbal, tatos e intraverbais, é que ele permite uma correspondência discreta, ponto a ponto com os itens interpessoais que emergem entre eles. Descrições, se podem ser estendidas da psicoterapia para a vida diária, mudarão o controle funcional do comportamento do paciente, de formas encobertas para formas abertas, para além dos limites da situação terapêutica.

3. Um Repertório Verbal Aumenta o Reforçamento Positivo e Reduz o Controle Aversivo. Há conseqüências práticas amplas com a presença ou ausência de um repertório verbal que corresponda ao próprio comportamento do indivíduo, ao comportamento dos outros e à maneira pela qual eles se controlam. Sem esse repertório, há pouca possibilidade de reduzir tanto a quantidade do controle aversivo como a quantidade de reforçamento intermitente e de extinção. $\mathrm{O}$ processo é análogo ao choque livre em um experimento com animal, quando comparado com outro precedido por um estímulo de aviso; ou uma ocorrência incerta de um reforçador positivo quando comparado com um fato claro que dá dicas quando um desempenho pode ser reforçado. Um repertório verbal que corresponda estreitamente às 
condiçôes de reforçamento e punição constitui visão previsível e ordenada de eventos que maximiza a freqüência de reforçamento positivo e minimiza o controle aversivo. Quando esse repertório está ausente, um corolário são os subprodutos emocionais, relacionados à extinção e ao reforçamento intermitente, que são descritos coloquialmente como perda, isolamento e desespero. $\mathrm{O}$ contraste entre uma vida diária ampliada pelo comportamento verbal sobre ela e a ausência de tal ampliação verbal é o contraste entre um mundo que é ordenado e previsível e um que é inconstante (Beck, 1967).

É frequentemente observado, por exemplo, que um paciente interrompido durante a terapia por freqüentes chamadas telefônicas pode não ser capaz de falar sobre suas queixas, seja abertamente ou intraverbalmente. A persistência e a magnitude de um aborrecimento podem ser tão grandes, no entanto, que invadem quase todos os outros tipos de interaçóes com o terapeuta, e o paciente falará sobre estar aborrecido, por não ter nada para dizer, ou sobre deixar a terapia ou o paciente pode chegar tarde para a próxima sessão. Se o paciente puder falar sobre sua própria reação e a relação com a atividade telefônica do terapeuta, há alguma possibilidade de ver os comportamentos de ambos claramente, e de influenciar ativamente os fatos importantes - as interrupções e a raiva resultante. A alternativa é uma mistura confusa de três ângulos de um triângulo: a observação da interrupção pelo paciente, seu aborrecimento e a visão do terapeuta como a pessoa responsável por tudo.

\section{REFERÊNCIAS}

Azrin, N. H. (1977). A strategy for applied research. Learning based but outcome oriented. American Psychologist, 32, 140-149.
Beck, A. (1967). Depression. Philadelphia: Univ. of Pennsylvania Press.

Creed, T. L., \& Ferster, C. B. (1972). Space as a reinforcer in a continuous free-operant environment. Psychological Record, 22, 161-167.

Dollard, J., \& Miller, N. (1950). Personality and psychotherapy. New York: McGraw-Hill.

Estes, W. K. (1944). An experimental study of punishment. Psychological Monographs, 57, (Whole No. 263), 40-107.

Eysenck, H. J. (1957). The dynamics of anxiety and hysteria. New York: Praeger.

Ferster, C. B. (1967a). Arbitrary and natural reinforcement. Psychological Record, 17, 341-347.

Ferster, C. B. (1967b). The transition from laboratory to clinic. Psychological Record, 17, 145-150.

Ferster, C. B. (1972a). Clinical reinforcement. Seminars in Psychology, 4, 2.

Ferster, C. B. (1972b). The experimental analysis of clinical phenomena. Psychological Record, 22, 1-16.

Ferster, C. B. (1974). The difference between behavioral and conventional psychology. Journal of Nervous and Mental Diseases, 159, 153-157.

Ferster, C. B. (in press). A functional analysis of verbal aspects of depression. Em Laboratory models of depression. New York: Academic Press.

Ferster, C. B. (1979). A laboratory model of psychotherapy. The boundary between clinical practice and experimental psychology. Em P. O. Sjoden, S. Bates \& W. S. Dockens, III (Orgs.). Trends in behavior therapy. New York: Academic Press.

Ferster, C. B., \& Hummer, C. E. (1966). The synthesis of arithmetic behavior in chimpanzees. Em W.K. Honig (Org.). Operant behavior: Areas of research and application (pp. 634-676). New York: Appleton.

Ferster, C. B., \& Simmons, J. (1966). An evaluation of therapy with children. Psychological Record, 16, 6571.

Ferster, C. B., Nurenberger, J., \& Levitt, E. B. (1962). 
The control of eating. Journal of Mathetics, 1, 87110.

Ferster, C. B., \& Skinner, B. F.(1957). Schedules of reinforcement. New York: Appleton.

Findley, J. (1962). An experimental outline for building and exploring multi-operant behavior repertoires. Journal of the Experimental Analysis of Behavior, 3, 113-166.

Glover, F. (1955). The technique of psychoanalysis. London: Bailliere, Tindall and Cox.

Guthrie, E. R. (1935). The psychology oflearning. New York: Harper.

Hartmann, H. (1950). Comments on the psychoanalytic theory of the ego. Em Ruth S. Eissler et al (Org.). Psychoanalytic study of the child, Vol. 5. New York: International Universities Press.

Hull, C. L. (1943). Principles of behavior. New York: Appleton.

Keehn, J. D., \& Webster, C. B. (1969). Behavior therapy and behavior modification. The Canadian Psychologist, 10, 68-73.

Keller, F. S., \& Schoenfeld, W. N. (1950). Principles of psychology. New York: Appleton.

Lewin, K. (1935). Dynamic theory of personality. New York: McGraw Hill.

Mahoney, M. J. (1977). Reflections on the cognitivelearned trend in psychotherapy. American Psychologist, 32, 5-13.

Masserman, J. M. (1943). Behavior and neurosis. Chicago: Univ. of Chicago Press.

Miller, N. E. (1944). Experimental studies in conflict. Em J. McV. Hunt (Org.). Personality and the behavior disorders, Vol. 1. New York: Ronald Press. Pavlov, I. P. (1927). Conditioned reflexes. London: Oxford Univ. Press.
Rogers, C. R. (1965). Client-centered therapy. Boston: Houghton-Mifflin.

Searles, H. (1965). Neutral therapist responses. Em Collected papers on schizophrenics and related subjects. New York: International Universities.

Skinner, B. F. (1938). The behavior of organisms. New York: Appleton.

Skinner, B. F. (1948). Walden Two. New York: McMillan.

Skinner B. F. (1953). Science and human behavior. New York: McMillan.

Skinner, B. F. ( 1957). Verbal behavior. New York: Appleton.

Skinner, B. F. (1958). Teaching machines. Science, 128, 969-977.

Skinner, B. F. (1968). The technology of teaching. New York: Appleton.

Solomon, R. L. (1977). An opponent-process theory of acquired motivation: The affective dynamics of addiction. Em J. D. Maser, \& M. E. P. Seligman (Orgs.). Psychopathology: Experimentalmodels (p.66103). San Francisco: Freeman.

Tolman, E. C. (1932). Purposive behavior in animals and men. New York: Century.

Wachtel, P. (1977). Psychoanalysis and behavior therapy. New York: Basic Books.

Watson, J. B. (1919). Psychology from the standpoint of a behaviorist. Philadelphia: Lippincott.

Watson, J. B. (1930). Behaviorism (2nd ed.). New York: Norton.

Watson, R. (1968). The great psychologists. Philadelphia: Lippincott.

Wolpe, J. (1958). Psychotherapy by reciprocal inhibition. Palo Alto: Stanford Univ. Press.

Tradução recebida em 23 de fevereiro de 2007 


\section{REVISTA BRASILEIRA DE ANALISE DO COMPORTAMENTO}

\section{Instruções para preparação de manuscritos}

A Revista Brasileira de Análise do Comportamento é uma publicação semestral que visa divulgar a Análise do Comportamento no Brasil e no exterior, publicando trabalhos originais em português ou inglês nas categorias artigo teórico, análise conceitual, relato de pesquisa pleno e breve. A revista também publica artigo que contribui para a preservação da história do Comportamentalismo e da Análise do Comportamento, e a tradução de artigos clássicos.

\section{INFORMAÇŌES SOBRE A SUbMISSÃO de MANUSCRITOS}

Para assegurar que o processo editorial seja rápido e eficiente, verifique se o manuscrito atende às normas da revista, e segue as regras gramaticais e de estilo de redação científica.

O manuscrito e todas as correspondências relacionadas a ele devem ser enviados ao Editor por email no endereço rebac.bjba@gmail.com. A correspondência entre o Editor e o autor responsável pelo envio do manuscrito sobre assuntos relativos ao processo de revisão serão apenas via e-mail.

A mensagem eletrônica para submissão do manuscrito deve indicar o título do trabalho, o nome dos autores, o número de figuras, tabelas e arquivos anexados à mensagem.

Manuscritos submetidos à ReBAC devem serguir as nomas de estilo e organização descritas no Publication Manual of the American Psychological Association (5th edition, 2001) e devem utilizar normas semelhantes às do Journal of the Experimental Analysis of Behavior. Apenas manuscritos que estiverem em conformidade com essas exigências serão avaliados.

O manuscrito deverá ser enviado como um arquivo no format Rich Text (.rtf) ou MS-Word (.doc) para rebac.bjba@gmail.com. Nenhuma cópia em papel enviada pelo correio será aceita.

Todo manuscrito deve estar acompanhado por uma carta de encaminhamento ao editor afirmando que os autores concordam que a revista conduza o processo editorial, bem como que o estudo foi conduzido seguindo-se os princípios éticos. A carta deve conter o nome de todos os autores e a afirmação de que o manuscrito não está sendo avaliado e nem será submetido à avaliação em outra revista durante o processo editorial em curso na ReBAC. Os arquivos, incluindo a carta e o manuscrito, devem ser enviados por e-mail ao Editor, com cópia para todos os autores.

O processo editorial terá início apenas se todas as exigências acima forem cumpridas, caso contrário o manuscrito será devolvido para que as modificações e inclusōes sejam realizadas.

O Editor acusará imediatamente o recebimento do manuscrito.

\section{CONSIDERAÇÕES ÉTICAS}

\section{Tratamento dos sujeitos.}

Qualquer aspecto não usual do procedimento de experimentos relatados que podem ter estressado os sujeitos experimentais deve ser justificado na descrição dos propósitos do estudo. Os revisores serão encorajados a comentar se esses aspectos são apropriados ou não. Além disso, assume-se que pesquisas submetidas à publicação na ReBAC seguiram os Princípios Éticos da APA para Psicólogos. Manuscritos com suspeita de violação desses princípios necessitarão de revisão que justifique os métodos e técnicas utilizadas. Informação adicional sobre os Princípios Éticos da APA podem ser encontradas no exemplar de Março de 1986 do Journal of the Experimental Analysis of Behavior e nas normas da APA para Condução Ética no Cuidado e Uso de Animais. Guarda e Compartilhamento de dados.

Autores com artigos publicados podem receber solicitações de envio dos dados originais (brutos) dos quais derivaram as análises apresentadas no artigo. $\mathrm{O}$ solicitante pode ter interesse em realizar novas análises, para, eventualmente, examinar a adequação de um modelo ou de uma interpretação alternativa. É esperado que os autores concordem com tais solicitações cooperativamente e prontamente. Os autores devem guardar os dados originais por um período de pelo menos 5 anos a partir da data de publicação.

\section{Formato e OrganizaÇão}

Digite o manuscrito com margens de $3,2 \mathrm{~cm}(1,25$ polegadas), espaço duplo (incluindo referências, figuras, título de figuras e tabelas). Use fonte Times New Roman tamanho 12 pontos. $\mathrm{O}$ manuscrito não deve exceder 40 páginas incluindo referências, tabelas, etc. Para que a tarefa 
de diagramação seja menos árdua e mais rápida, use um editor de texto compatível com o MS-Word e utilize o mínimo de comandos automáticos do programa. Apenas uma fonte de ser utilizada. Negrito, itálico e outros elementos de estilo não devem ser utilizados. As palavras que devem aparecer em itálico no texto impresso devem ser sublinhadas no manuscrito.

Organize o manuscrito na seguinte sequência:

- Primeira página - Folha de rosto com o nome dos autores. A primeira página deve incluir:

1. Título em Português e Inglês com no máximo 15 palavras. A tradução para o Português pode ser solicitada ao Editor no caso de autores que não dominem a língua portuguesa.

2. Nome dos autores.

3. Afiliação institucional e país dos autores.

4. Sugestão de título curto na língua que o manuscrito foi redigido, o qual aparece no topo de páginas ímpares na versão final impressa. Esse título não deve exceder 4 palavras.

5. Endereço completo para correspondência, incluindo código postal, número de telefone e e-mail do autor de contato.

6. Nota do autor com agradecimentos e informaçôes sobre financiamento.

O manuscrito será avaliado por pelo menos dois revisores, membros do corpo editorial ou revisores ad hoc. A primeira página com os nomes dos autores será omitida para os revisores. Os autores são responsáveis por informações no corpo do trabalho que identifiquem a autoria do manuscrito.

- Segunda página - Título sem nome de autores. Esta segunda folha de rosto omite a identificação dos autores. Deve-se incluir nessa página:

1. Título em Português e Inglês.

2. Sugestão de título curto.

- Terceira página-Resumo. A terceira página deve conter: 1. Resumo em Português de no máximo 200 palavras. Tradução para o português pode ser solicitada ao Editor por autores que não dominem a língua portuguesa.

2. Palavras-chave: mínimo de três e máximo de 5 palavras digitadas com letras minúsculas e separadas por vírgula. Liste palavras-chave em ordem decrescente de importância, com exceção das relativas à resposta investigada que deve ser a penúltima e à caracterização dos sujeitos, listada por último. Consulte o índice do número 2 de cada volume da ReBAC para sugestôes.

- Quarta página-Abstract. A quarta página deve conter: 1. Resumo em Inglês (Abstract) de no máximo 200 palavras.

2. Key words: mínimo de três e máximo de 5 palavras digitadas com letras caixa baixa e separadas por vírgula. Key words devem ser equivalentes às palavras-chave $\mathrm{e}$ também listadas em ordem decrescente de importância.

Atenção: Resumos em português e inglês devem ser equivalentes e completos com não mais do que 20 linhas. Os resumos devem sumarizar os objetivos do estudo, o procedimento geral, os principais resultados e as conclusões obtidas do trabalho experimental. Não utilize abreviaçôes, exceto em casos especiais para aumentar a clareza do texto. Evite citação de referências, exceto quando essencial para esclarecer alguma idéia muito importante. Evite frases não informativas e vagas tais como: "Várias explicações dos resultados foram discutidas".

- Quinta e demais páginas - Corpo do artigo. O texto deve incluir uma introdução (não escrever o título Introdução) seguida pelo Método, Resultados e Discussão, nesta ordem. Organização das seçōes diferente desta deverá ser evitada e só será aceita quando necessário para melhorar a clareza do texto. Em alguns casos Resultados e Discussão podem ser apresentados juntos, embora esse procedimento não seja recomendado.

Depois do texto, inclua em nova página e na seguinte ordem as informações: Referências, Nota do autor, Notas de rodapé, Tabelas, Títulos de figuras, Figuras e Apêndices.

O texto deve ser estruturado com no máximo 5 níveis de seção e subseção.

\section{Corpo do Trabalho}

Essa parte do manuscrito deve iniciar em uma nova página. Todas as páginas a partir dessa seção deverão ser numeradas de forma consecutiva e iniciando pelo número cinco (5). Os subtítulos (ou subseçôes) devem ser formatados de acordo com as normas da APA que limita em, no máximo, 5 níveis. 
Um artigo divulga novos procedimentos e achados e, portanto, deve ser claro e conciso. Use frases curtas e diretas. Os procedimentos e o comportamento resultante devem ser descrito como tendo ocorrido no passado. Princípios gerais, provavelmente verdadeiros por muito tempo, devem ser discutidos em tempo presente. Se o autor conseguir justificar a violação de uma convenção, a forma utilizada deve ser consistente em todo o texto. $\mathrm{O}$ Manual de Publicação da APA (pp. 70-76) apresenta técnicas para reduzir vieses em várias expressões convencionais.

\section{INTRODUÇÃO}

A Introdução (não intitulada assim no texto) deve fornecer uma racional sucinta para o estudo. Nessa seção deixe claro quais questōes serão abordadas e porque é interessante respondê-las. A Introdução deve mencionar a literatura relevante e identificar problemas que a pesquisa foi delineada para esclarecer.

Regras de Citação devem ser observadas. Reconheça a autoria e indique as datas de publicação de todos os trabalhos citados. Todos os nomes de autores devem ser seguidos pelo ano de publicação quando o trabalho é citado pela primeira vez em cada parágrafo. Citações literais de texto devem ser digitadas entre aspas, com a indicação das páginas de onde foram copiadas. No caso de citação literal mais longa do que 40 palavras, a margem esquerda deve ser maior do que o resto do texto. Todas as citações de citações devem indicar as referências originais, embora esse tipo de citação deva ser evitado, especialmente quando o trabalho original for de fácil acesso. Caso necessário, entretanto, o sobrenome do autor do original, o ano de publicação, o sobrenome do autor da citação e data de publicação devem ser indicados. A citação de um conjunto de referências juntas no corpo do trabalho deve ser feita em ordem alfabética e não cronológica.

\section{MÉTODO}

A descrição do método deve permitir ao leitor compreender o que foi realizado e replicar o estudo.

Sujeitos. Essa seção deve descrever as características relevantes dos sujeitos. De acordo com o Manual de Publicação (p. 19), sujeitos animais não-humanos devem ser identificados pelo gênero, espécie e linhagem ou pelo nome e localização do fornecedor. Forneça informação relevante sobre o número, idade, peso, condiçôes fisiológicas e características gerais do tratamento e manuseio dos animais. Inclua informações sobre as histórias experimentais dos animais e a forma de determinação da redução de peso. Sujeitos nãohumanos devem ser descritos pela sua espécie e não filo. Por exemplo, utilizar "pombos" em vez de "ave" para descrever os primeiros. Para sujeitos humanos, inclua informações, quando relevante, sobre fatores como gênero, escolaridade, uso de drogas psicoativas, diagnóstico clínico, e medidas de funcionamento intelectual para indivíduos com probabilidade de estarem fora dos parâmetros de normalidade.

Equipamento. Forneça informação suficiente para permitir replicação.

Estímulos. Inclua figuras ou diagramas de estímulos difíceis de descrever.

Procedimento. Forneça uma descrição bem organizada do que foi feito. Geralmente é útil indicar resumidamente a racional para a programação das condiçôes. Para sujeitos humanos, inclua a cópia de todas as instruções.

\section{RESULTADOS}

Esta seção deve fornecer uma descrição coerente, organizada e objetiva dos efeitos importantes das variáveis independentes (e.g., relações funcionais e tendências).

\section{DISCUSSÃO}

A Discussão deve focalizar em como os resultados respondem as questôes levantadas na Introdução e como eles ajudam a esclarecer e estender princípios.

\section{REFERENNCIAS}

Esta seção deve iniciar em nova página. Referências devem ser organizadas em ordem alfabética pelo sobrenome do autor e deve ser digitada em espaço duplo. $\mathrm{O}$ uso de espaço em branco entre referências não é permitido. Cada referência deve aparecer em um novo parágrafo. Recomenda-se aos autores que revejam cuidadosamente as regras da revista e as normas da APA antes de elaborarem as referências bibliográficas, para que todos os critérios sejam obedecidos. 
O texto deve fazer contato adequado com a literatura relevante através das referências.

Confira cada referência com a fonte original.

Não dependa de outras listas de referência, pois elas podem conter erros.

Faça uma dupla conferência para verificar discrepâncias entre as citações no texto e na lista de referências, incluindo o ano de publicação.

Certifique-se de que todas as citações no texto aparecem na lista e vice-versa.

Dados não publicados de dissertações podem ser citados na lista de referência, mas não é apropriado apelar para outros dados não publicados, como aqueles apresentados em congressos, para apoiar um argumento. Tais dados não estão disponíveis para o leitor examinar. Apresentaçôes em congresso que auxiliam o pesquisador a definir um procedimento ou a introduzir um conceito, entretanto, devem ser reconhecidas e citadas no texto e referenciada em nota de rodapé em vez de na lista de referências.

Siga as normas do Manual de Publicação da APA (pp.215-281) para formatar as citações e a lista de referências. Segue abaixo exemplos de como devem ser formatadas as fontes de referência mais comuns.

Livro

Sobrenome, Iniciais. (ano de publicação). Título. Local: Editora.

Danna, M.F., \& Matos, M.A. (1982). Ensinando observação. São Paulo: Edicon.

Catania, A.C., \& Harnad, S. (Eds.). (1988). The selection of behavior: The operant behaviorism of B.F. Skinner: Comments and consequences. Cambridge, MA: Cambridge University Press.

\section{Capitulo de Livro}

Sobrenome, Iniciais. (ano de publicação). Título do capítulo. In Iniciais e sobrenome (Ed.), Titulo do livro (pp. primeira-última página do capítulo). Local: Editora.

Catania, A.C. (1988). The operant behaviorism of B. F. Skinner. In A. C. Catania, \& S. Harnad (Eds.), The selection of behavior: The operant behaviorism of B. F. Skinner, Comments and consequences (pp. 3-8). Cambridge, MA: Cambridge University Press.

Williams, B.A. (1988). Reinforcement, choice, and response strength. In R. C. Atkinson, R. J. Herrnstein, G. Lindzey, \& R. D. Luce (Eds.), Stevens' handbook of experimental psychology: Vol.2. Learning and cognition (pp. 167-244). New York: Wiley.

\section{Artigo em Periódico Científico}

Sobrenome, Iniciais. (ano de publicação). Título do artigo. Periódico, Volume, primeira-última página.

Petroski, H. (1995). Soft graphics. American Scientist, 83, 17-20.

Todorov, J.C. (1989). A psicologia como estudo de interações. Psicologia: Teoria e Pesquisa, 5, 347-352.

\section{NOTAS DE RODAPÉ}

Em uma página separada, após a lista de referências, inclua a nota de rodapé denominada "Nota do Autor”. Este é o local para incluir agradecimentos, reconhecimentos e um endereço postal e eletrônico para que os leitores possam solicitar cópia do trabalho e informação adicional sobre a pesquisa. Evite outras notas de rodapé a menos que seja absolutamente necessário para a clareza do texto. Em geral, se o material éimportante, inclua-o no texto; se não for importante, remova-o. Notas de rodapé indispensáveis devem ser endereçadas no texto por números romanos e descritas na seção de Notas de Rodapé.

\section{FIGURAS E TABELAS}

Figuras e tabelas devem ser apresentadas com legendas e títulos, cada qual em uma nova página. $\mathrm{O}$ título de uma tabela aparece no topo da tabela em caixa baixa e deve indicar seu conteúdo. O título de uma figura deve aparecer abaixo da figura e deve seguir as mesmas especificações das tabelas.

Os títulos de tabelas e os cabeçalhos devem tornar o conteúdo inteligível sem referência ao texto. No caso de tabelas complexas, descriçôes detalhadas mas breves podem ser apropriadas como parte do título da tabela. Consulte o Manual de Publicação para uma descrição completa sobre como preparar tabelas.

As figuras são especialmente eficazes para mostrar tendências e, em geral, são o foco da seção de Resultados. É importante, portanto, que elas sejam preparadas com cuidado e com uma formatação efetiva.

As figuras devem ser enviadas com o arquivo de texto e como arquivos adicionais no formato do software que foram originalmente preparadas (Excel ou Photoshop; jpg, tiff ou pict; $300 \mathrm{dpi}$ ).

As figuras devem ser completas e suficientemente claras para serem compreendidas sem o título. 
Utilize o espaço de forma eficiente; coloque as legendas no espaço em branco dentro dos limites da figura. Os símbolos, curvas e marcações de registro-cumulativo devem ser rotuladas de maneira apropriada.

Quando preparar uma ilustração de página inteira, considere que o espaço deve contemplar também o título. As figuras podem ser reduzidas durante o processo de diagramação.

Evite tipos achatados, com linhas grossas e não utilize negrito. As letras e números em fontes altas, estreitas e com linhas finas são reproduzidas com melhor visibilidade (e.g., Helvética ou Arial). Letras com tamanho uniforme, em caixa alta ou baixa que melhor se ajustem à área disponível podem ser utilizadas. É melhor utilizar caixa alta e baixa de um tamanho legível do que utilizar apenas letras maiúsculas de tamanho menor e mais difícil de ler.

O mesmo estilo de fonte deve ser consistentemente utilizado em todas as figuras.

Quando for possível, mantenha informações explicativas (identificação dos sujeitos, número de sessão, etc.) no corpo da figura em vez de acima, abaixo ou ao lado.

Símbolos dos dados. Quando símbolos vazios forem escolhidos para representar os dados, utilize linhas finas em símbolos que sejam grandes o suficiente para, no caso de necessidade de redução, garantir a distinção entre as diferentes formas utilizadas (círculo, triângulo e quadrado).

Eixos e linhas. Evite linhas pesadas nos eixos porque elas podem dar a impressão de que as fontes finas e os símbolos utilizados na figura estão desproporcionalmente finos.

Forneça marcas suficientemente espaçadas dos valores das escalas nos dois eixos, para evitar uma aparência muito cheia, mas permitir uma leitura razoavelmente precisa dos valores de x e y dos dados. Evite linhas grossas para representar funções teóricas ou para unir os pontos. Se tipos diferentes de linha forem utilizados para unir os pontos, escolha as linhas tracejadas com cuidado; os espaços entre traços devem ser suficientes para manter as separações no caso de redução da figura.

Não coloque moldura na figura.

Submeta as figuras no tamanho real que deseja na publicação para largura de uma ou duas colunas para que os revisores e editores possam julgar a sua adequação. As dimensões e proporçôes das páginas da revista são: altura $21 \mathrm{~cm}$; largura de uma coluna $7.0 \mathrm{~cm}$; e largura de duas colunas $14.5 \mathrm{~cm}$.
Numere todas as figuras consecutivamente com numerais Arábicos e na ordem que aparecem no manuscrito. Indique o local aproximado que cada figura deve aparecer no texto (e.g., INSIRA A FIGURAX).

Escreva o número da figura no canto superior direito de cada figura, junto com o nome do primeiro autor.

Títulos. Os títulos das figuras devem ser concisos, mas suficientemente completos para as figuras serem compreendidas sem necessidade de recorrer ao texto. $\mathrm{Na}$ versão publicada do artigo, as figuras serão colocadas próximas às descrições correspondentes no texto. Conseqüentemente, o texto não deve duplicar a descrição no título.

ANEXO

O Apêndice deve ser apresentado em página nova, depois da seção de Referências. Todas as páginas devem ser numeradas consecutivamente, em espaço duplo. Os anexos devem ser preparados apenas se for realmente essencial para a compreensão do texto. Os autores podem preferir informar os leitores através de uma nota sobre quais instrumentos ou outros materiais estão disponíveis e como consegui-los. Todos os anexos devem ser indicados no texto e identificados com letras maiúsculas (A, B, C, etc.).

\section{TERMOS TÉCNICOS E ABREVIAÇŌES}

Termos Técnicos. Os termos técnicos não são familiares a ninguém. Tais termos são necessários para a precisão do texto e não podem ser eliminados, mas eles devem ser explicados. Tal explicação geralmente pode ser incorporada no texto quando o termo é utilizado pela primeira vez, como no exemplo: Na presença de um estimulo, o $S^{D}$, bicadas eram reforçadas; na presença de outro estímulo, o $S^{\Delta}$, bicadas não eram reforçadas. Não introduza termos técnicos desnecessários. Pode ser muito útil consultar um glossário de termos técnicos.

Abreviaçôes. Não utilize abreviações no título; elas podem ser utilizadas de forma moderada no resumo para melhorar a clareza. Não inicie frases com abreviaçôes (ou numerais). Não abrevie experimentador com E, sujeito como $S$, número como N, ou resposta como R. Não introduza abreviações desnecessariamente. Economia de espaço raramente justifica abreviaçôes, embora elas algumas vezes podem ser úteis para fins de concisão, tais como frases em Latin (i.e., e.g., etc.) usadas entre 
parênteses, e com unidades físicas padrões (cc, dB, kg, $\mathrm{ml}, \mathrm{N}, \mathrm{mA}, \mathrm{s}$ ) quando acompanhadas por número. Essas unidades não são seguidas por ponto exceto quando ocasionar confusão, como in. para inch no meio do texto em inglês. As palavras Figura e Experimento, mesmo quando seguidas por um número, não são abreviadas no texto. Para uma discussão completa sobre a utilização de abreviações, veja pp. 103-111 do Manual de Publicação.

\section{REVISANDO O MANUSCRITO E NORMAS PARA A SUBMISSĀO} DA VERSÃO FINAL ACEITA

Os autores dos manuscritos aceitos e que não precisam realizar modificaçôes substanciais devem enviar ao Editor uma cópia digital (rebac.bjba@gmail.com) da versão final acompanhada por carta assinada por todos os autores, indicando que os direitos autorais de reprodução e divulgação do artigo serão da Revista Brasileira de Análise do Comportamento.

Os autores de manuscritos recomendados para publicação sob a condição de que sejam feitas revisões baseadas nos comentários dos revisores devem enviar ao Editor a cópia digital (rebac.bjba@gmail.com) do manuscrito revisado, juntamente com uma carta que descreve todas as mudanças introduzidas no manuscrito. Nos casos em que os autores decidiram não aceitar alguma modificação sugerida, eles devem justificar tal decisão. $\mathrm{O}$ conteúdo desta carta sem a identificação da autoria e o manuscrito revisado serão enviados a um membro do Corpo Editorial ou ao Editor Associado responsável para a revisão final.

\section{REVISĀO FINAL}

Antes de enviar os manuscritos para impressão, o Editor enviará a cópia do artigo diagramado para uma revisão final do autor. Essa revisão deverá ser feita em dois dias úteis e as modificações de forma necessárias antes da impressão devem ser informadas ao Editor até esse período. No caso dos autores não enviarem o manuscrito com as últimas revisões, o Editor assumirá que os autores aceitaram o material na sua forma corrente. 


\section{Lista para ConferênCia do Autor}

Faça uma revisão cuidadosa do manuscrito antes de submetê-lo. Erros gramaticais e ortográficos causam uma impressão de descuido do autor e podem influenciar a avaliação do seu trabalho. Leve em consideração as regras e padrōes relativos à língua e às exigências da revista. Confira os seguintes itens:

\section{Primeira submissão}

Envie para rebac.bjba@gmail.com (endereçado ao Editor e com cópia para todos os autores):

1) Mensagem eletrônica ao Editor submetendo o manuscrito à avaliação na ReBAC e incluindo o título do trabalho, o nome dos autores, o número de figuras, tabelas e arquivos anexados à mensagem.

2) Carta de Encaminhamento ao Editor com o nome dos autores e título do manuscrito contendo:

( ) autorização para o periódico conduzir o processo editorial;

( ) afirmação de que todos os procedimentos éticos foram respeitados;

( ) afirmação de que o manuscrito não está sendo avaliado e nem será submetido à avaliação em outra revista durante o processo editorial em curso na ReBAC.

3) Cópia digital do manuscrito (formato Rich Text, WordPerfect ou MS-Word Windows ou Macintosh). O manuscrito deve estar de acordo com as normas $\mathrm{da}$ revista e CUIDADOSAMENTE revisado:

\section{( ) Espaço duplo}

( ) Folha de rosto com nome dos autores (inclui nota do autor com o endereço e e-mail para correspondência e agradecimentos)
( ) Folha de rosto sem o nome dos autores

( ) Resumo em Português

( ) Palavras-chave em Português

( ) Resumo em Inglês

( ) Palavras-chave em Inglês

( ) Referências em espaço duplo (conferi a formatação e verifiquei se todas as informações foram fornecidas para cada referência, e se todas as referências citadas no texto foram incluídas na lista)

( ) Notas (somente as realmente essenciais, como a Nota do autor)

( ) Tabelas e Figuras (confira se a localização que deve aparecer no texto foi indicada e se o formato e tamanho estão de acordo com as instruções para submissão)

( ) Anexo (apenas se realmente essencial).

\section{Manuscrito Revisado}

Envie para rebac.bjba@gmail.com (endereçado ao Editor e com cópia para todos os autores):

( ) Carta ao Editor especificando todas as mudanças feitas no texto e justificando aquelas sugestôes não atendidas

( ) Manuscrito revisado (utilize novamente a lista de conferência do manuscrito; inclua novamente a primeira folha de rosto com a identificação dos autores que foi retirada no processo editorial).

\section{Manuscrito Aceito}

Envie para rebac.bjba@gmail.com (endereçado ao Editor e com cópia para todos os autores):

( ) Carta ao Editor afirmando que os direitos autorais são da revista, assinada por todos os autores ( ) Versão final do manuscrito, totalmente conferido (nenhuma mudança de conteúdo será aceita após o envio desta versão, portanto assegure que uma revisão completa foi feita antes de enviar a versão final). 


\section{BRAZILIAN JOVRNAL OF BEFAVIOR ANALYSIS}

Guide for preparation of papers

The Brazilian Journal of Behavior Analysis is a biannual publication which aims to disseminate Behavior Analysis in Brazil and abroad, including original work in the format of theoretical article, conceptual analysis, research report and brief research report in Portuguese or English. The journal will also include articles which help to build the history of Behaviorism and Behavior Analysis and the translation to Portuguese of classical articles.

\section{SUBMISSION INFORMATION}

To ensure a fast and efficient editorial process, check that the manuscript conforms to the journal's guidelines, with Portuguese or English grammar and style.

Manuscripts and all correspondence should be sent to the Editor at rebac.bjba@gmail.com. Correspondence between the Editor and submitting author on matters related to the review process will be via e-mail only.

The submission e-mail message should indicate the title of the manuscript, author names, the number of figures, tables, and files attached to the message.

Manuscripts submitted to BJBA should conform the style and organization described in the Publication Manual of the American Psychological Association (5th edition, 2001) and should use similar guidelines from the Journal of the Experimental Analysis of Behavior. Only the Manuscripts conforming to these requirements will be evaluated.

The manuscript should be submitted as a rich text file or MS-Word file to rebac.bjba@gmail.com. No paper copy sent by post will be accepted.

Each manuscript should be accompanied by a covering letter to the editor stating that: (1) authors agree to the journal conducting the editorial process, (2) the study was conducted according to ethical principles, and (3) the manuscript will not be submitted to another journal at the same time as submitted to $B J B A$. The letter should have the name of all authors. Manuscript and letter files should be sent by e-mail to the Editor and copied to all authors.

The editorial process only begins if manuscripts fulfill the requirements above. Non-conforming manuscripts will be returned to authors for modifications.

Manuscripts will be immediately acknowledged by the Editor.

\section{Evaluation Process}

Manuscripts will be evaluated by at least two reviewers, members of the editorial board or ad hoc reviewers. The first page with author names will be omitted for reviewers. Authors are responsible for information that allows identification of authorship of the manuscript.

\section{ETHical Considerations}

\section{Treatment of Subjects.}

Any unusual procedural features of reported experiments that might have stressed the experimental subjects should be justified in the stated rationale for the experiment. Reviewers are encouraged to comment on the appropriateness or inappropriateness of such features when they are encountered. Further, it is assumed that research submitted for publication in BJBA conforms to the APA Ethical Principles of Psychologists. Manuscripts suspected of violating these principles will require revision justifying the methods and techniques used. Additional information about APA Ethical Principles may be found in the March 1986 issue of the Journal of the Experimental Analysis of Behavior and in the APA Guidelines for Ethical Conduct in the Care and Use of Animals.

Retaining and Sharing Data.

It is not uncommon for authors of published papers to receive requests for the original (raw) data from which the summary data in the paper were derived. The requesting individual might wish to analyze the data in a different way, perhaps to examine the adequacy of a model or to consider the plausibility of an alternative interpretation. Authors are expected to comply with such requests cooperatively and promptly. Authors should retain the original data for a period of at least 5 years from the time of publication.

\section{FORMAT AND ORGANIZATION}

Type the manuscript with $3.2-\mathrm{cm}$ (1.25-in) margins, double spaced throughout (including references, figure captions, and tables). Use font TimesNew Roman size 12 point. Articles should be no more 
than 40 pages including references, tables, etc. In order to make desktop publishing tasks easier and faster, authors are asked to use WordPerfect or MS-Word for Windows or Macintosh, as well as for applying a minimum of commands. Only one font should be used. Bold, italic, and other style elements should not be used. Words which must appear in italic in the printed text should be underlined in the manuscript.

Organize the manuscript in the following sequence:

\section{- First page - Cover page with author names. Cover page should include:}

1. Title both in Portuguese and English (maximum of 15 words). Translation to Portuguese may be required to the Editor by non-Portuguese speaking authors.

2. All author names.

3. Institutional affiliation and country of each author.

4. Short title in the language that the manuscript was written, which will appear at the top of odd-numbered pages. This title should not exceed 4 words.

5. Complete mailing address, including zip (post) code, telephone number, and e-mail address of corresponding author.

6. Author Note with acknowledgments at least address and e-mail for correspondence should appear in footnote.

Note: Manuscripts are sent to reviewers without the identification of authors. Therefore, the title page must be the only one stating manuscript's authorship. The authors alone are responsible for ensuring that no element in the text be able to identify their authorship.

- Second page - Cover page without author names. This page should include: Title in Portuguese and English, and suggested running head in the language that the manuscript was written.

- Third page-Resumo. Third page should include:

1. Abstract in Portuguese (maximum of 200 words long). Translation to Portuguese may be required to the Editor by non-Portuguese speaking authors.

2. Keywords in Portuguese: minimum of three and maximum of five, typed in lower-case letters and separated by a colon. List key words in descending order of importance, with the only exception being that the response under study and the species of the subjects should be listed last. Consult the Index in number 2 of each Volume of $B J B A$ for suggestions.
- Forth page-Abstract. Fourth page should include.

1. Abstract in English should be maximum of 200 words long.

2. Keywords in English: minimum of three and maximum of five, typed in lower-case letters and separated by a colon. Keywords should be equivalent to Palavras-chave and also listed in descending order of importance. Consult the Index in number 2 of each Volume of $B J B A$ for suggestions.

Attention: Abstracts in Portuguese and English should be equivalent and complete with no more than 20 lines. Abstracts should summarize the aims of the study, the general procedure, the major findings and the conclusions drawn from the experimental work. Do not use abbreviations unless they provide clarity, and avoid reference citations except when necessary to make an important point. Avoid uninformative or unspecific sentences such as: "Several explanations of the results were discussed".

- Fifth and successive pages - Body of the article. The text including an Introduction (not labeled as such) followed by Method, Results, and Discussion. Depart from this organization only when necessary for clarity. In some cases, Results and Discussion can be presented together, although this procedure is not recommended.

After the text, start each of the following in order on a separate page: References, Author Note, Footnotes, Tables, Figure Captions, Figures, and Appendixes.

Note: Use no more than 5 levels of section and subsection.

\section{BODY OF THE ARTICLE}

This part of the manuscript should start in a new page. All pages from this point on should be numbered consecutively starting from number five (5). Subtitles should be formatted according to APA guidelines with the limit of 5 levels.

An article communicates new procedures and findings and therefore should be clear and concise. Use short and direct statements. Procedures and the resulting behavior are described as having occurred in the past. General principles, presumably true for all time, are discussed in the present tense. If an author can justify violating a convention, the resulting usage should be consistent throughout the text. The Publication Manual (pp. 70-76) presents techniques for reducing bias in many conventional expressions. 


\section{INTRODUCTION}

The Introduction (not labeled as such) should provide a succinct rationale for the study. It should make clear which questions about principles are being addressed and why these questions might be interesting to answer. The Introduction should mention the relevant literature and identify gaps which the research is designed to fill.

Citation rules should be observed. Attribution to authors and indication of publication dates of all cited works should be given. All author names should be followed by the year of publication when their works are cited for the first time in each paragraph. Literal excerpts of a text should be typed within double quotation marks, and a citation of the page from which they were copied; in the case of extensive citations (longer than 40 words), their left margin should be larger than the rest of the text. All citations of citations should state their original references, although this kind of citation should be avoided, especially when the original can be easily accessed. However, if needed, author's last name of the original, date, author's name of the citation and publication date should be stated. When several references are cited in a series in the body of the paper, they should be listed in alphabetical, not chronological, order.

\section{METHOD}

The description of the method should enable the reader to comprehend what was done and to replicate the study.

Subjects. This section should describe the relevant characteristics of the subjects. As noted in the Publication Manual (p. 19), nonhuman animal subjects should be identified by genus, species, and strain or by the name and location of the supplier (stock designation). Provide relevant information about the number, age, weight, physiological condition, and the general treatment and handling of animals. Include information about the animals' experimental histories and the manner of determining reduced weights. Nonhuman subjects should be described by its species rather than its phylum. For example, "pigeon" should be used rather than "bird" when describing the former subjects. For human subjects, include information, as relevant, on such factors as gender, use of psychoactive drugs, clinical diagnosis, and measures of intellectual functioning for individuals likely to be outside the normal range.

Apparatus. Provide enough information to permit replication.

Stimuli. Include pictures or diagrams of difficultto-describe stimuli.

Procedure. Provide a well-organized description of what was done. It often helps to indicate briefly the rationale for the various conditions. For human subjects, include a verbatim copy of all instructions given.

\section{RESULTS}

This section should provide a coherent, organized, and objective description of the important effects of the independent variables (e.g., trends and functional relations).

\section{DISCUSSION}

The Discussion should focus on how the data answer the questions raised in the Introduction and how they help clarify or extend principles.

\section{REFERENCES}

This section should start on a new page. References should be arranged in alphabetical order according to the surname of the author and should be typed with double spacing. The use of a blank space between references is not allowed. Each reference should appear as a new paragraph. A hanging indent at left margin should be used (a simple tab indent). Authors are recommended to carefully review the journal's rules before preparing bibliographical references, in order to meet all criteria.

The text should make adequate contact with relevant literature through references.

Check each reference against the original source.

Do not depend on other reference lists as they can be wrong.

Double check for discrepancies between citations in the text and the reference list, including the year of publication.

Be sure all references in the text appear on the list, and vice versa.

Unpublished data from dissertations may be cited in the reference list, but it is not appropriate to appeal to 
other unpublished data, such as those presented at meetings, to support an argument. Such data are not available in archival form for readers to examine. A contribution at a meeting that established a researcher's priority in devising a procedure or introducing a concept, however, should be acknowledged in the text and referenced in a footnote instead of in the reference list.

Follow the guidelines in the Publication Manual (pp. 215-281) for the format of citations and the reference list. Find below examples of the common sources of reference:

\section{Book}

Surname, Initials. (publication year). Title. Place: Editor.

Danna, M.F., \& Matos, M.A. (1982). Ensinando observação. São Paulo: Edicon.

Catania, A.C., \& Harnad, S. (Eds.). (1988). The selection of behavior: The operant behaviorism of B.F. Skinner: Comments and consequences. Cambridge, MA: Cambridge University Press.

\section{Book Chapter}

Surname, Initials. (publication year). Chapter title. In Initials and Surname (Ed.), Book title (pp. first-last chapter page). Place: Editor.

Catania, A.C. (1988). The operant behaviorism of B.F. Skinner. In A. C. Catania, \& S. Harnad (Eds.), The selection of behavior: The operant behaviorism of B.F. Skinner, Comments and consequences (pp. 38). Cambridge, MA: Cambridge University Press.

Williams, B.A. (1988). Reinforcement, choice, and response strength. In R. C. Atkinson, R. J. Herrnstein, G. Lindzey, \& R. D Luce (Eds.), Stevens' handbook of experimental psychology: Vol.2. Learning and cognition (pp. 167-244). New York: Wiley.

\section{Article in Scientific Journal}

Surname, Initials. (publication year). Article title. Journal, Volume, first-last page.

Petroski, H. (1995). Soft graphics. American Scientist, 83, 17-20.

Todorov, J.C. (1989). A psicologia como estudo de interaçôes. Psicologia: Teoria e Pesquisa, 5, 347-352.

\section{FOOTNOTES}

On a separate page following the references, include a footnote labeled "Author Note." This is the place to include acknowledgments and an address (including e-mail) so that readers can request a reprint or additional information about the research. Avoid other footnotes unless absolutely necessary for clarity. In general, if the material is important, include it in the text; if it is unimportant, delete it. Indispensable footnotes should be identified in the text by Arabic numbers, and appear on the same page under the title "Notes".

\section{FIGURES AND TABLES}

Figures and tables should be presented along with their respective captions and titles, each one on a new page. The title of a table should appear at the top of it in lower case and should indicate its contents. The title of a figure should appear below it and should follow the same specifications for tables.

Table title and headings should make the contents intelligible without reference to the text. For complex tables, brief but detailed descriptions may be appropriate, to be presented as part of the table title. Tables should not exceed $7.0 \times 21 \mathrm{~cm}$ (single column) or $14.5 \times 21.0$ $\mathrm{cm}$ (double column), including titles. For a full discussion on how to prepare tables, see the Publication Manual.

Figures are especially effective for revealing trends and are often the focus of the Results section. It is important that they be prepared carefully and with effective design.

Figures should be sent with text file and as additional files in original software format (Excel or Photoshop; jpg, tiff or pict; $300 \mathrm{dpi}$ )

Figures should be complete and clear enough to be understood without the caption.

Use space efficiently; place legends in white space within the borders of the figure. Symbols, curves, and cumulative-record markings should be appropriately labeled.

When preparing a full-page illustration, consider that space must be allowed for the caption. Figures may be reduced during the editing process.

Avoid squat, heavy-lined, boldface type. Tall, narrow letters and numbers having thin lines reproduce well (e.g., Helvetica or Arial font). Lettering uniformly sized, capitals or upper and lower cases may be used to fit in the area available. It is better to use upper and lower cases in a readable size than it is to use all capitals in a smaller, more-difficult-to-read size.

The same font style should be used consistently on all figures. 
Where possible to do so without obscuring the data presented, keep explanatory matter (subject identification, session number, and so on) within the body of the figure rather than above, below, or to one side.

Data points. Unfilled data points must be constructed of thin lines and must be large enough so that reduction will neither make different shapes indistinguishable nor fill in unfilled circles, triangles and squares.

o Axes and lines. Avoid heavy lines for axes because they may make thin-lined lettering and data points appear disproportionately light. Crop the vertical and horizontal axes. Provide scale marks along both axes spaced sufficiently to avoid a crowded appearance but to permit a reasonably accurate reading of the $\mathrm{x}$ and y values of the data points. Avoid heavy lines to represent theoretical functions or to connect data points. If different kinds of lines are used to connect data points, choose broken lines carefully; the spaces at the breaks must be open enough to be readily evident when reduced.

Do not frame the figure.

Submit figures in the actual size for publication in one-column or two-column width so that reviewers and editors can judge their adequacy. Dimensions and proportions of the journal's page are:

Height: $21 \mathrm{~cm}$.

Single-column width: $7.0 \mathrm{~cm}$.

Double-column width: $14.5 \mathrm{~cm}$.

Number all figures consecutively with Arabic numerals in the order in which they appear in the manuscript, indicating their placement in the text (e.g., INSERT FIGURE X ABOUT HERE).

o Write the appropriate figure number in the upper right corner of each figure, along with the first author's name.

Captions. Figure captions should be concise but complete enough that figures can be understood without reference to the text. In the published version of the paper, figures will be placed close to the corresponding passages in the text. Consequently, the text should not duplicate material in the captions.

\section{APPENDIX}

The Appendix should be presented on new pages after the references. All pages should be consecutively numbered, with double spacing. Annexes should be prepared only if they are really essential for the understanding of the text. Authors can choose to inform readers through a note on what instruments or other material are available and how to get them. All appendixes should be indicated in the text, and identified with capital letters (A, B, C, etc.).

\section{TECHNICAL TERMS AND ABBREVIATIONS}

Technical terms. Technical terms are not familiar to everyone. Such terms are necessary for precision and cannot be eliminated, but they should be explained. This explanation usually can be incorporated into the text when a term is first used. For example: In the presence of one stimulus, the $S^{D}$, pecks were reinforced; in the presence of the other, the $S^{\mathrm{D}}$, pecks were not reinforced. Do not introduce unnecessary technical terms. It may be useful to consult a glossary of technical terms.

Abbreviations. Do not use abbreviations in the title; they may be used sparingly in the abstract to improve clarity. Do not begin sentences with abbreviations (or numerals). Do not abbreviate experimenter as $\mathrm{E}$, subject as $\mathrm{S}$, number as $\mathrm{N}$, or response as $\mathrm{R}$. Do not introduce abbreviations unnecessarily. Space saving rarely justifies abbreviations, though abbreviations sometimes may be useful for conciseness, such as with common Latin phrases (i.e., e.g., etc.) used parenthetically, and with standard physical units (cc, dB, kg, ml, N, mA, s) when accompanied by numbers. The latter are not followed by periods except to avoid confusion, as in. for inch. The words Figure and Experiment, even when followed by a number, are not abbreviated in the text. Do not abbreviate terms for combinations of schedules (e.g., multiple, concurrent). For a fuller discussion of the use of abbreviations, see pp. 103111 of the Publication Manual.

\section{REVIEWING THE MANUSCRIPT AND GUIDELINES BEFORE SUBMITTING THE FINAL VERSION}

Authors of accepted manuscripts not requiring significant changes should send to the Editor a digital copy accompanied by a statement signed by all authors indicating that the copyright will be held by Brazilian Journal of Behavior Analysis. 
Authors of manuscripts recommended for publication with the condition that revisions be made according to the comments of the reviewers should send to the Editor the revised manuscript by e-mail, accompanied by a letter describing all changes introduced in the manuscript. In the case authors decide not to accept some of the suggested changes, they should justify such a decision. This letter and the revised manuscript will be sent to a member of the Editorial Board for a final review. The Editor and
Associate Editor are responsible for the final decision. FINAL REVIEW

Before sending manuscripts for printing, the Editor will send galleys for authors' revision. This revision should take two working days, after which the manuscript should be sent back to the Editor. In the case authors do not send the manuscript back indicating corrections, the editor will assume that authors have accepted the material in its present form. 


\section{CHeCKLIST}

Carefully review your manuscript before submitting. Take into account all rules and standards relating to language and journal requirements. Check the following items.

\section{First submission}

Send to rebac.bjba@gmail.com (addressed to the Editor and copied to all authors):

1) Submission e-mail message containing: title of the manuscript, author names, the number of figures, tables, and files attached to the message.

2) Accompanying letter to the Editor with all author names containing:

( ) authorization to journal to begin editorial process;

( ) statement assuring that all ethical procedures have been respected;

( ) statement assuring that the manuscript will not be submitted to another journal at the same time as submitted to $B J B A$.

3) Digital copy of the manuscript (rich text, WordPerfect or MS-Word in Windows or Macintosh format) should be sent to rebac.bjba@gmail.com. Manuscript should be in accordance to journal's guidelines, and CAREFULLY reviewed:

( ) double spacing

( ) title page with author names (include author note with at least address and e-mail for correspondence and acknowledgement)

( ) title page without author names

( ) abstract in Portuguese

( ) keywords in Portuguese

( ) keywords in English

( ) references in double spacing (check format and complete information for each reference item, as well as the inclusion of all references mentioned in text)

( ) Notes (if essential, except Author note)

( ) Tables and Figures (check if their location in the text is indicated and if format and size is according to submission instructions)

( ) Appendix (if really essential).

\section{Reviewed manuscript}

Send to rebac.bjba@gmail.com (addressed to the Editor and copied to all authors):

( ) Letter to the Editor specifying all changes made in the text and justifying those suggestions not accepted

( ) Revised manuscript including first page with authors' name

\section{Accepted manuscript}

Send to rebac.bjba@gmail.com (addressed to the Editor and copied to all authors):

( ) Letter to the Editor assigning the copyright exclusively to the journal, signed by all authors ( ) Final version of the manuscript (no other changes will be accept in the manuscript, therefore be sure a complete review was made of the whole text before sending it). 


\title{
BRAZILIAN GRADUATE PROGRAMS IN BEHAVIOR ANALYSIS
}

Programa de Pós-Graduação em Teoria e Pesquisa do Comportamento

\author{
Instituto de Filosofia e Ciências Humanas \\ Universidade Federal do Pará
}

Cursos: Mestrado e Doutorado

Docentes da área de Análise do Comportamento:

\author{
Carla Cristina Paiva Paracampo \\ Carlos Barbosa Alves de Souza \\ Emmanuel Zagury Tourinho \\ Eleonora Arnaud Pereira Ferreira \\ Grauben José Alves de Assis \\ Luis Carlos de Albuquerque \\ Marcelo Quintino Galvão Baptista \\ Marcus Bentes Carvalho Neto \\ Marilice Fernandes Garotti \\ Olavo de Faria Galvão \\ Olívia Misae Kato \\ Romariz da Silva Barros \\ Informaçōes adicionais: www.ufpa.br/ppgtpc \\ Contatos: (91)3201-7662 ou comporta@ufpa.br
}




\title{
BRAZILIAN GRADUATE PROGRAMS IN BEHAVIOR ANALYSIS
}

PROGRAMA DE PÓS GRADUAÇÃO EM PSICOLOGIA EXPERIMENTAL

Áreas de concentração:

\author{
ANÁLISE EXPERIMENTAL DE CONTINGÊNCIAS COMPORTAMENTAIS \\ COMPORTAMENTO ANIMAL E ETOLOGIA HUMANA \\ PROCESSOS COGNITIVOS, AFETIVOS E SOCIAIS NO SER HUMANO \\ PROBLEMAS TEÓRICOS E METODOLÓGICOS DA PESQUISA PSICOLÓGICA
}

Departamento de Psicologia Experimental

Universidade de São Paulo

\section{Cursos: MESTRADO E DOUTORADO}

Docentes da área de concentração em Análise do Comportamento

Gerson Aparecido Yukio Tomanari

Maria Helena Hunziker

Maria Martha Costa Hübner

Maria Teresa Araújo Silva

Paula Debert

Página da internet para obter informações adicionais e e-mail para contato $w w w . i p . u s p . b r$ 